Portland State University

PDXScholar

TREC Final Reports

Transportation Research and Education Center

(TREC)

4-2017

\title{
Dynamic Evaluation of Transportation Structures with iPod-Based Data Acquisition
}

Charles Riley

Oregon Institute of Technology

Follow this and additional works at: https://pdxscholar.library.pdx.edu/trec_reports

Part of the Civil Engineering Commons, and the Transportation Engineering Commons Let us know how access to this document benefits you.

\section{Recommended Citation}

Riley, C. Dynamic Evaluation of Transportation Structures with iPod-Based Data Acquisition. NITC-ED-985. Portland, OR: Transportation Research and Education Center (TREC), 2017. https://doi.org/10.15760/ trec. 166

This Report is brought to you for free and open access. It has been accepted for inclusion in TREC Final Reports by an authorized administrator of PDXScholar. Please contact us if we can make this document more accessible: pdxscholar@pdx.edu. 


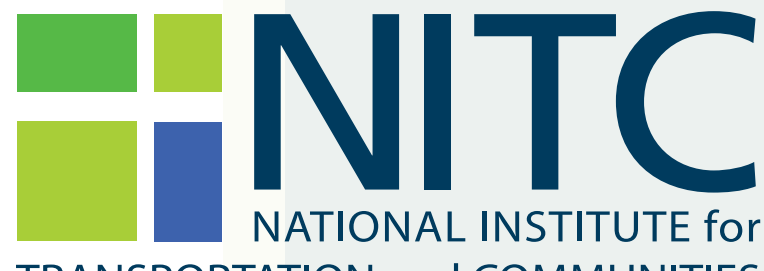

TRANSPORTATION and COMMUNITIES

\section{FINAL REPORT}

Dynamic Evaluation of Transportation Structures with iPod-Based Data Acquisition

NITCN-ED-985 $\square \quad$ April 2017

NITC is a U.S. Department of Transportation national university transportation center.

HI!" TREC 



\section{DYNAMIC EVALUATION OF TRANSPORTATION STRUCTURES WITH IPOD-BASED DATA ACQUISITION}

\section{Final Report}

\section{NITC-ED-985}

by

Charles E. Riley

Oregon Institute of Technology

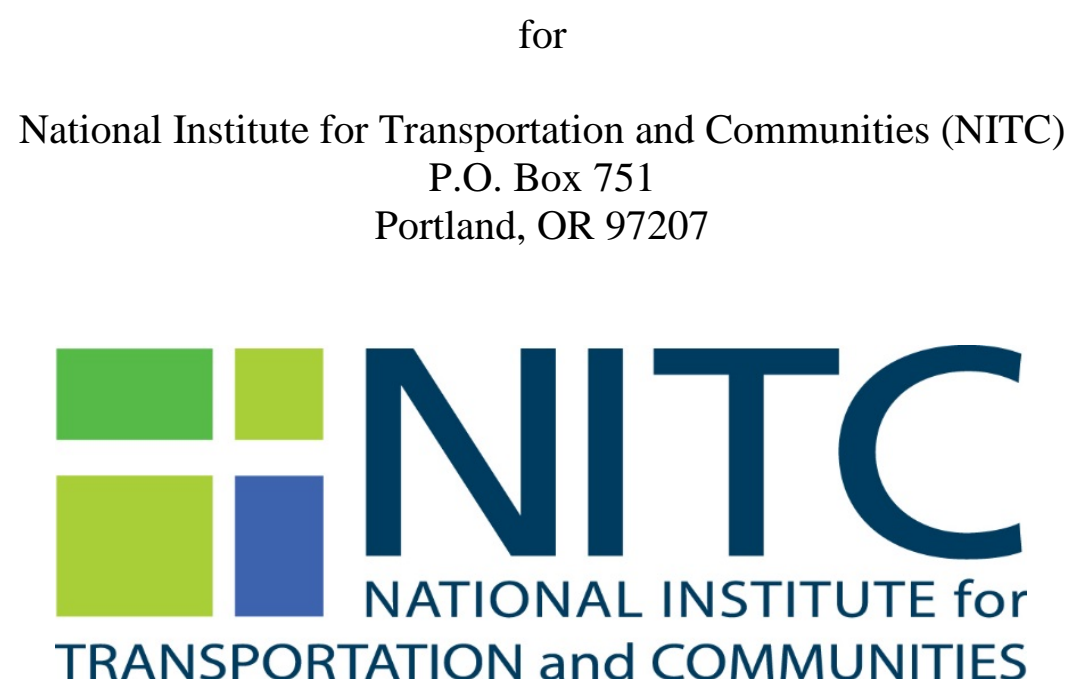

April 2017 


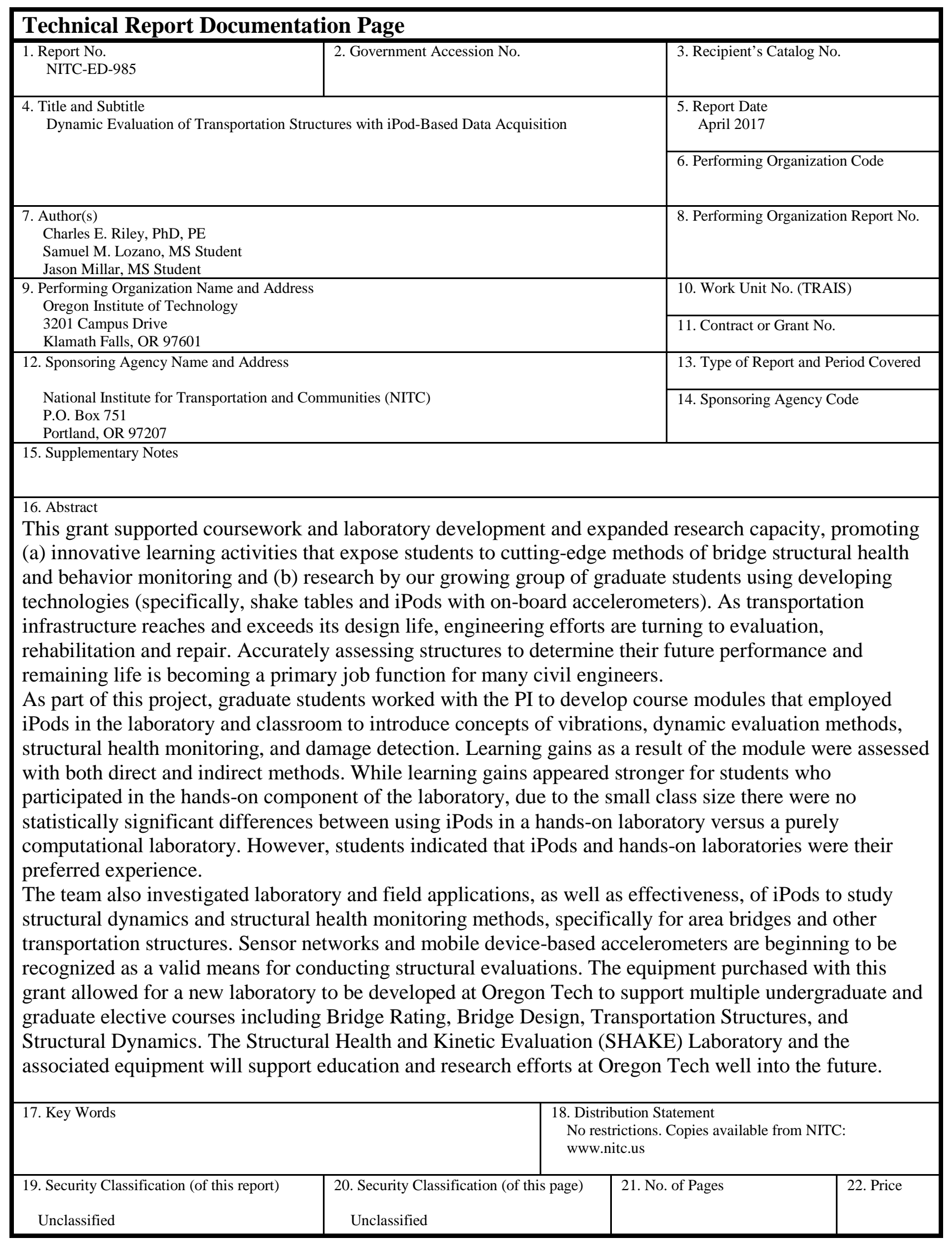




\section{ACKNOWLEDGEMENTS}

The project team would like to acknowledge the generous support of NITC for the work documented in this report. The development of the laboratory and curriculum in the area of transportation and infrastructure health, as well as the increased capacity for applied research at Oregon Tech, would not have been possible without the institute's assistance.

\section{DISCLAIMER}

The contents of this report reflect the views of the authors, who are solely responsible for the facts and the accuracy of the material and information presented herein. This document is disseminated under the sponsorship of the U.S. Department of Transportation University Transportation Centers Program in the interest of information exchange. The U.S. Government assumes no liability for the contents or use thereof. The contents do not necessarily reflect the official views of the U.S. Government. This report does not constitute a standard, specification, or regulation.

\section{RECOMMENDED CITATION}

Riley, Charles. Dynamic Evaluation of Transportation Structures with iPod-Based Data Acquisition. NITC-ED-985. Portland, OR: Transportation Research and Education Center (TREC), 2017. 


\section{TABLE OF CONTENTS}

EXECUTIVE SUMMARY …........................................................................................................ 1

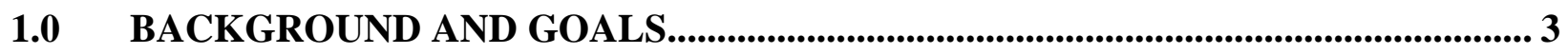

2.0 APPROACH................................................................................................................ 7

3.0 METHODOLOGY …….................................................................................................. 9

3.1 CURRICULUM DEVELOPMENT ……………………………………………...... 9

3.2 LABORATORY MODULE DEVELOPMENT ............................................................. 9

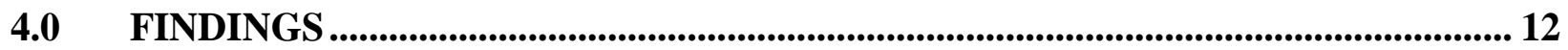

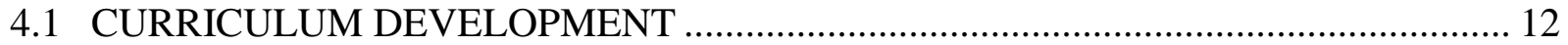

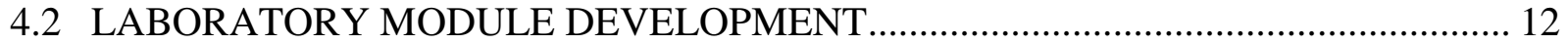

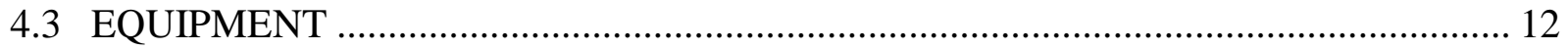

5.0 DEVELOPMENT OF RESEARCH CAPACITY AT OREGON TECH.................... 14

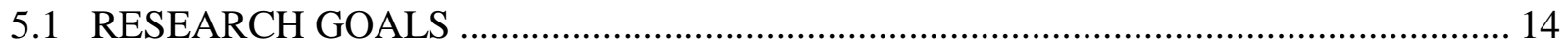

5.1.1 iPods for Data Collection..................................................................................... 14

5.1.1.1 Evaluation of iPods for use as acceleration sensors ............................................ 14

5.1.1.2 Evaluation of iPods for use in a wireless sensor network ..................................... 14

5.1.2 Other Methods of Developing Acceleration Sensor Networks................................. 15

5.1.3 Shake Table Capabilities....................................................................................... 15

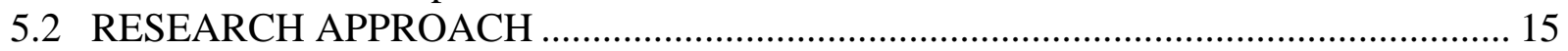

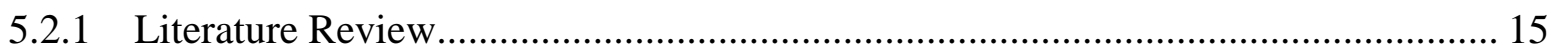

5.2.2 iPod Sensor Network ..................................................................................... 16

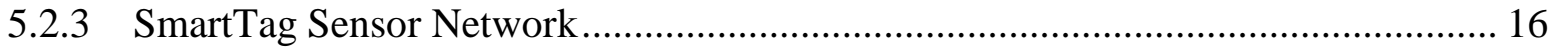

5.2.4 Virtual Visual Sensors ...................................................................................... 16

5.2.5 iPod Accelerometer Evaluation ..................................................................... 16

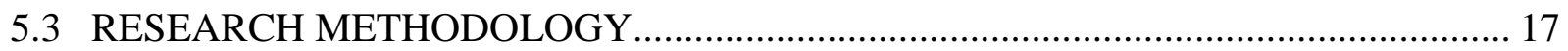

5.3.1 iPod Networking ………………...................................................................... 17

5.3.2 iPod Accelerometer Evaluation .............................................................................. 17

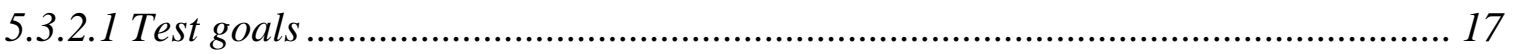

5.3.2.2 Data processing .............................................................................................. 18

5.3.2.3 SensorTag development ………………………................................................ 22

5.4 RESEARCH FINDINGS ......................................................................................... 22

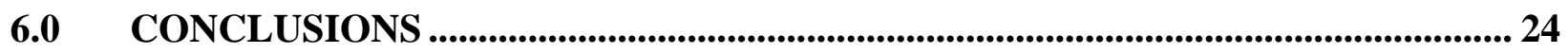

6.1 EDUCATION PROJECT CONCLUSIONS ……….................................................. 24

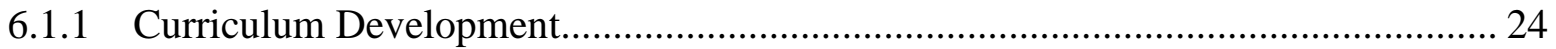

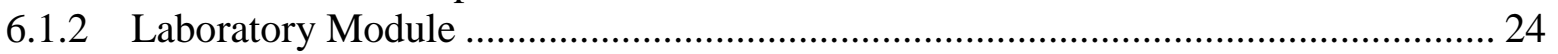

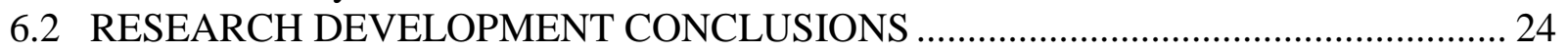

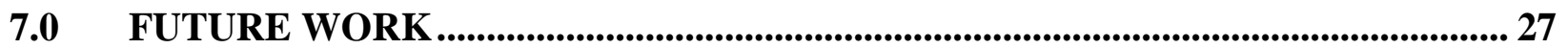

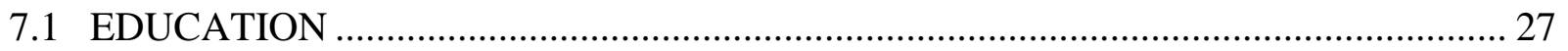

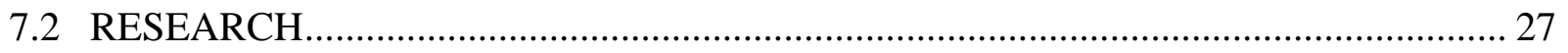

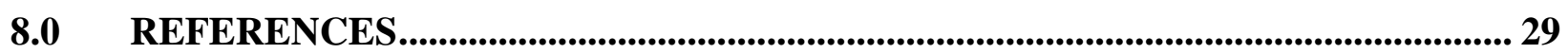




\section{APPENDICES}

APPENDIX A: ASEE PAPER 2016, POSTERS

\section{LIST OF FIGURES}

Figure 1.1: Quanser Shake Table I-40 and accelerometer ............................................................... 3

Figure 1.2: $3^{\text {rd }}$ Generation iPods for acceleration data collection..................................................... 3

Figure 1.3: Texas Instruments SensorTag, networkable multisensor platform ................................ 4

Figure 3.1: Students measure intentional section loss in laboratory structure.............................. 10

Figure 3.2: Tip-loaded cantilever used in laboratory module................................................... 10

Figure 5.1: Quanser I-40 shake table with iPod and Quanser accelerometer .................................. 17

Figure 5.2: Results of accuracy evaluation of Quanser accelerometer ......................................... 18

Figure 5.3: Results of accuracy evaluation of iPod accelerometer ............................................... 19

Figure 5.4: Summary of data reduction process used to determine accelerometer limits ............. 20

Figure 5.5: Comparison of limits of Quanser and iPod accelerometers ...................................... 22 


\section{EXECUTIVE SUMMARY}

This project supported coursework and laboratory development and expanded research capacity at Oregon Tech, promoting (a) innovative learning activities that expose students to cutting-edge methods of bridge structural health and behavior monitoring and (b) research by our growing group of graduate students with new equipment, specifically iPods with on-board accelerometers, Texas Instruments SensorTags, virtual visual sensors, and a benchtop shake table capable of scale-model dynamic structural response demonstrations and accelerometer testing. Collectively, the equipment will comprise the Structural Health and Kinetic Evaluation

(SHAKE) Laboratory at Oregon Tech. The educational module developed and assessed as part of this project will continue to be revised and expanded in the future to be featured or modified for use in at least four elective courses.

In recent years, the number of structurally deficient bridges in the United States has increased dramatically as structures built during the Eisenhower administration have reached and exceeded their design life. Many of these deficient bridges are inspected and maintained more frequently, resulting in increased costs to departments of transportation (DOTs). Many DOTs are considering structural health monitoring for their most critical bridges, and seeking ways to minimize inspection costs or reduce inspection time (FHWA Long-Term Bridge Performance Study). Graduate students worked with the PI to develop course modules that employed iPods in a laboratory setting to introduce structural dynamics and structural health monitoring methods. From an education perspective, this engaging laboratory introduced students to various topics in structural health monitoring and bridge evaluation, including damage detection.

While the research team initially intended to develop an iPod sensor network in a way that would allow simultaneous data collection from multiple devices, we encountered difficulties on a number of fronts:

1) iOS apps that are not maintained or updated for new platforms resulted in crashing or incompatibility with purchased devices.

2) Simultaneous data collection with time-stamping precision at the level required for postprocessing of accelerometer data was not likely achievable with UDP streaming.

iPod accelerometers were evaluated to determine the range of applicability and precision compared to higher-precision equipment. iPods used individually were still determined to be a valuable addition to a laboratory designed to support structural dynamics and health monitoring education.

From a research perspective, sensor networks and smart device-based accelerometers are just beginning to be recognized as a valid means for conducting structural evaluations. The equipment requested in this proposal allowed for numerous studies that could lead to published works that would serve to increase the research capacity of the civil engineering department at Oregon Tech. This grant expanded the research capability of the university as expected and has supported two years of graduate work by two students. Continuing funding from NITC is 
supporting further work in the areas of vehicle dynamics and safety of roadway geometries, and collaboration with Portland State University (PSU) faculty. It also is supporting the PI and at least two more students in further development of a rapidly deployable structure evaluation system. 


\subsection{BACKGROUND AND GOALS}

The goals of this education grant were to support laboratory and curricular development related to structural dynamics, structural health monitoring and structural damage detection, specifically as they apply to transportation structures like bridges, light poles and sign structures. The primary goal, articulated in the grant proposal, was to determine the feasibility of using iPods in a sensor network to evaluate dynamic parameters of transportation structures. The educational goal was to develop curricular materials to support this sort of work and implement it in a laboratory setting.

The grant supported the purchase of this equipment:

- A Quanser Shake Table I-40 (Figure 1.1) with research-grade accelerometers, for benchtop testing of model structures and evaluation of acceleration sensors.
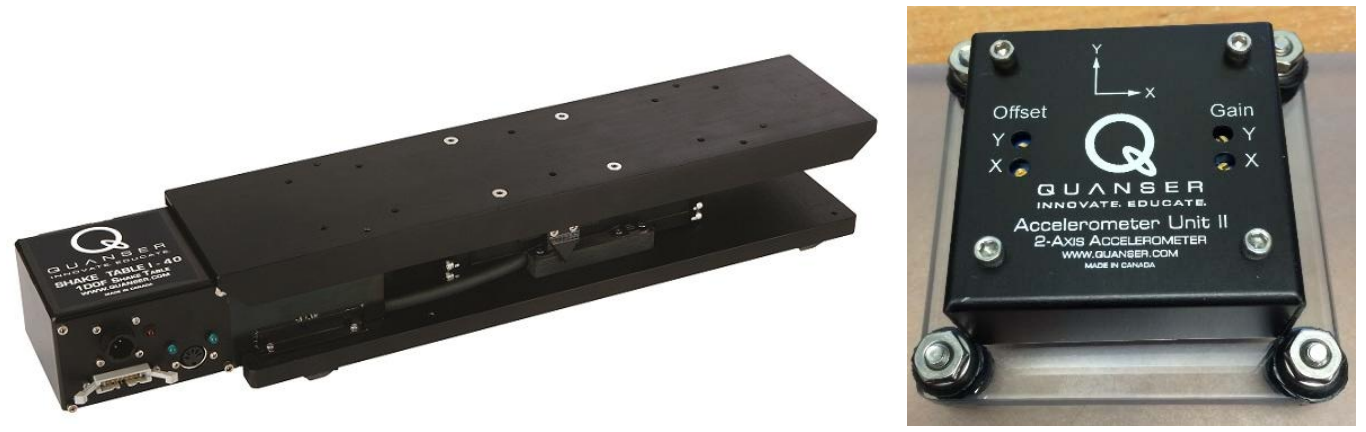

Figure 1.1: Quanser Shake Table I-40 and accelerometer

- $\quad$ Twelve (12) $3^{\text {rd }}$ Generation iPod Touch mobile devices (Figure 1.2) for use in laboratory activities and to conduct a feasibility study for use as an accelerometer sensor network.

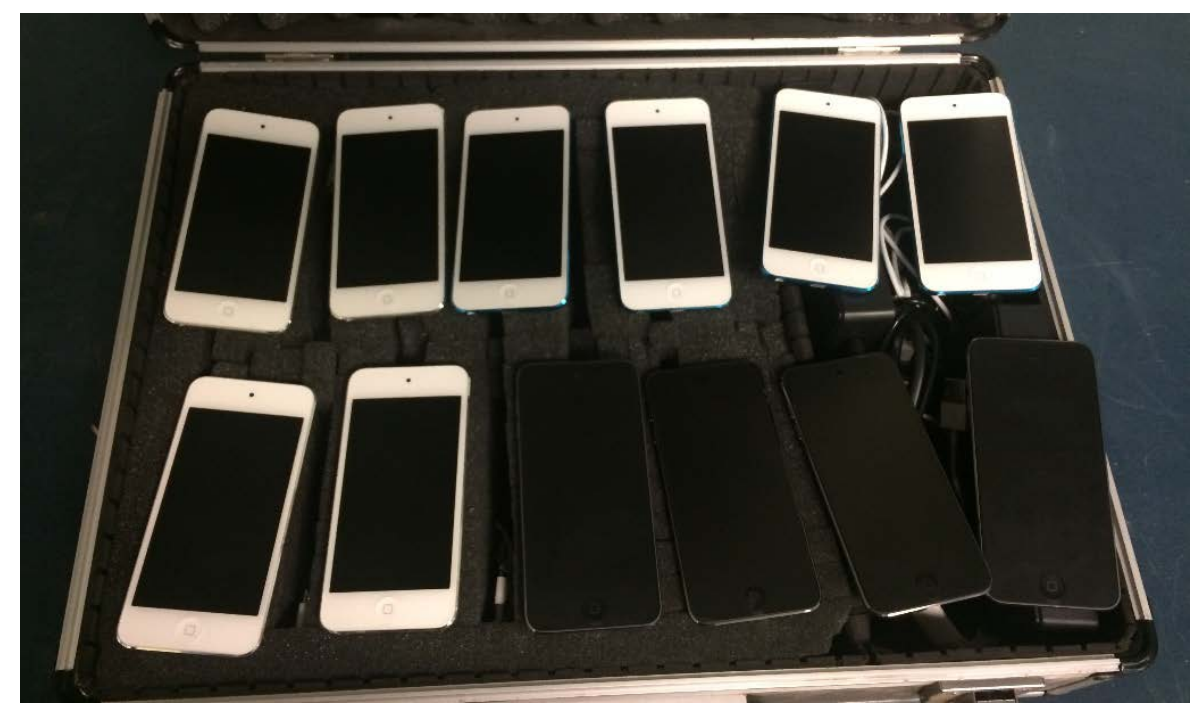

Figure 1.2: $3^{\text {rd }}$ Generation iPods for acceleration data collection 
- Ten (10) Texas Instruments SensorTags (Figure 1.3) for use in laboratory activities to measure acceleration as well as light, sound, magnetism, temperature, humidity, and pressure.

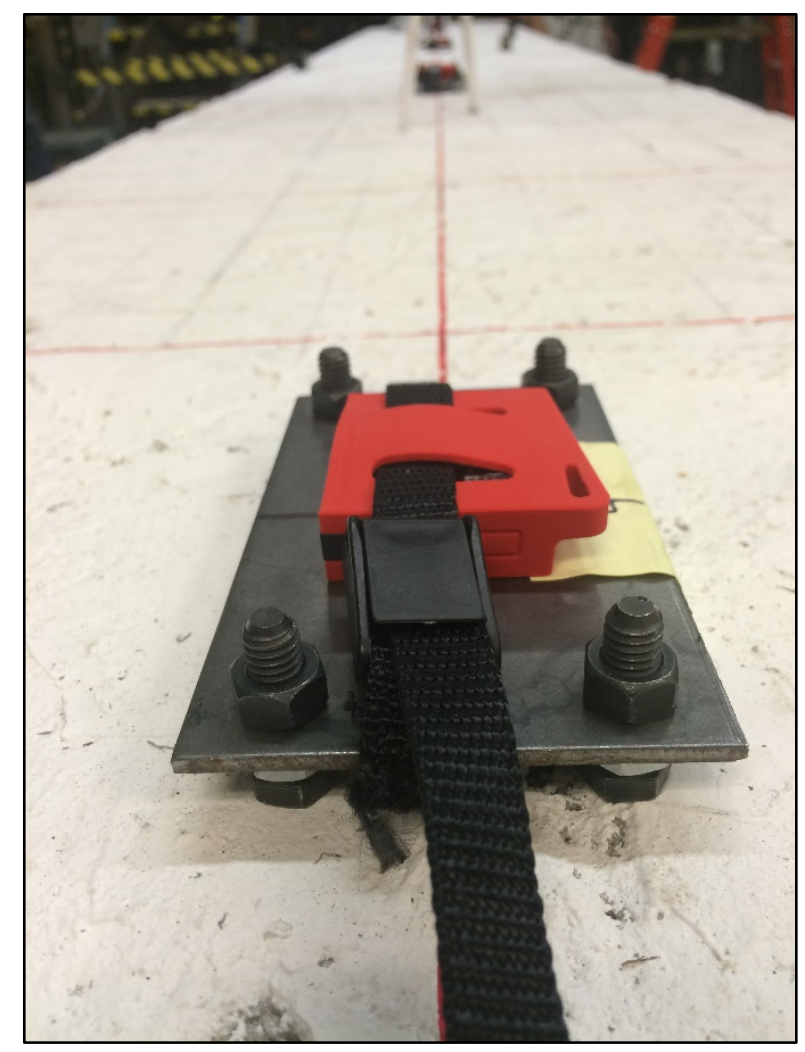

Figure 1.3: Texas Instruments SensorTag, networkable multisensor platform

This equipment supports Oregon Tech’s approach to teaching via laboratory and hands-on experiences. While many structural dynamics courses are taught around the country, entirely in the classroom, educational models promoted by the American Society of Civil Engineer via their Excellence in Civil Engineering Education (ExCEEd) Teaching Workshop as well as countless other active learning pedagogies have demonstrated the effectiveness of hands-on experiences (Estes et al., 2005; Feisel and Rosa, 2005). The benchtop shake table provides a platform to observe structural response to various types of excitation from harmonic to random, and take a structural dynamics course from a purely deductive mode, in which theoretical principles are presented and applied, to a more effective inductive mode, where observations are made and theoretical principles are developed and confirmed. This approach has been promoted, and curricular materials developed, for three decades by the University Consortium for Instructional Shake Tables (UCIST, 2016). Faculty at NITC partner institution Portland State University (PSU) also teach with this equipment and use similar pedagogical principles, which allows for education and research collaborations to thrive in the future.

This grant supported work by the PI and student research assistants to develop curricular materials that employ (a) the shake table for demonstration and laboratory testing and (b) iPods for data collection. While the PI had developed some curricular materials in 2014 using a shake 
table loaned by Oregon State University, the grant allowed the project team to revise and refine these materials for implementation in a CE449/549 Bridge Design elective course and to finetune a previously crafted lab sequence for CE535 Structural Dynamics. These courses are part of a revised curriculum and graduate program developed in 2013 and supported by a previous NITC education grant. Thus, NITC support has been critical in our development of the master's degree at Oregon Tech and the transportation-related courses in particular.

Perhaps more specifically, this grant supported the research team's development and delivery of a laboratory module that introduced students to damage detection via dynamic evaluation of structures, and measured the learning gains associated with various modes of delivery: hands-on with iPods, no hands-on component, and simulated online delivery. The results of this work were published and presented by a student research assistant at the American Society for Engineering Education's $123^{\text {rd }}$ Annual Conference in New Orleans in June 2016, which is a first for the department. The conference paper can be found in the Appendix of this report. 


\subsection{APPROACH}

According to recent research in alternative teaching and learning practices in science- and engineering-based courses, students seem to respond more positively to inductive or active learning when compared with traditional lecture sessions (Prince, 2004). The purpose of this study was to evaluate the effect of using mobile devices in an active learning environment for courses in structural dynamics and structural health monitoring. In the context of this study, alternative teaching practices refer to non-traditional methods of instruction, including active, inductive and problem-based learning (PBL). The use of mobile devices in the classroom was intended for the purposes of data collection and clarifying the quantities measured. Active learning with the use of personal mobile devices is a relatively modern and sometimes controversial topic that often receives outstanding support or determined opposition

The wide use and acceptance of technology in the classroom provides an opportunity for students to interact more efficiently with information and peers in a learning environment. The interactive teaching methods discussed in this paper relate to active, inductive and PBL. Active learning is most generally defined as any instructional method of engaging students for the entire duration of the teaching contact time. In addition to traditional homework and examinations, active learning allows students to participate in collaborative activities that positively influence student attitudes and study habits for course material. Inductive learning encompasses interactive instruction techniques including inquiry learning, PBL, project-based learning, case-based teaching, and discovery learning. PBL incorporates relevant problems introduced at the beginning of instruction to provide context and motivation for the learning that remains. In response to recent research involving the introduction and use of alternative learning in the classroom, studies suggest that "students will retain information longer and perhaps develop enhanced critical thinking and problem-solving skills” if active learning methods are employed.

The use of devices in the classroom affects the perception of material by using relatable and convenient tools in a practical application. When used as a tool for active learning, such as data collection and analysis, rather than for low-level communication or recording, mobile device technology has the ability to foster the amplification, extension, reconstruction, and reorganization of knowledge in an interactive learning environment. Using devices in an active learning environment encourages a greater level of critical thinking and problem solving that supports good practice in engineering laboratories.

Precise data collection in the engineering field requires reliable and consistent results available in a laboratory, as well as in a field scenario. Utilizing mobile devices and smartphones to collect and measure data encourages students to experience the reality of engineering measurement with the ease of convenient data collection. Although the utilization of smartphone data collection is a relatively recent concept for structural dynamics and structural health monitoring, mobile devices have been and are currently in use as monitoring systems for transportation structures.

Researchers from Nokia Research Center Palo Alto, Navteq and UC Berkeley conducted an experiment known as Mobile Millennium, involving the implementation of a state-of-the-art 
mobile phone GPS data collection system to monitor traffic conditions and real-time traffic estimation. Following the experiment, researchers found that developing this mobile application would allow for the successful collection, analysis and reporting of traffic condition estimates. As in the use of GPS data for traffic condition estimation, the accelerometer component and iSeismometer app available for modern mobile devices have significant potential for damage detection and estimation of structural health in the field of structural engineering. 


\subsection{METHODOLOGY}

The methods used to develop the curriculum and educational module are articulated in the following sections.

\subsection{CURRICULUM DEVELOPMENT}

Structural dynamics and structural health monitoring concepts can be introduced and reinforced in multiple elective courses in the civil engineering curriculum at Oregon Tech. Structural dynamics concepts are already treated heavily in CE535 Structural Dynamics, but the course and laboratory in their initial offering (Spring 2015) were based on a shake table that had been loaned from Oregon State University. The shake table purchased as part of this grant ensures that this course will remain in the curriculum, and that the active learning laboratory used to reinforce theory continues to be used. The course syllabus, schedule, study guide, and laboratory assignments as developed in Spring 2015 are included in the Appendix of this report. Labs 1 and 2 from this course offering were modified to create the laboratory module that was delivered and assessed in Winter 2016 as part of this project.

The PI intends to incorporate structural dynamics concepts into other elective courses in a way that the material can stand alone or reinforce learning in other electives. The small size of our cohorts and small number of department faculty prohibits the department from creating prerequisite-driven course sequences. To provide flexibility to students and ensure timely degree completion, course material essentially stands alone but it is differentiated to provide a developmental experience for those students who may have encountered the material in previous courses. It is also presented with fundamental material for those students who are encountering it for the first time. Structural dynamics and health monitoring concepts can be incorporated into CE439/539 Highway Bridge Rating, CE449/549 Bridge Design, and CE450/550 Transportation Structures. Concepts may also be incorporated into lower-division coursework in the future, including ENGR101 Introduction to Engineering I, ENGR211 Engineering Mechanics: Statics, and ENGR213 Engineering Mechanics: Strength of Materials.

The next section describes the development of the laboratory module that was revised from the first offering of CE535 Structural Dynamics to provide a platform for introducing structural dynamics and damage detection. It was incorporated into the Winter 2016 offering of CE449/549 Bridge Design course to assess its effectiveness.

\subsection{LABORATORY MODULE DEVELOPMENT}

Drawing from concepts in structural dynamics and structural health monitoring, the PI and two graduate students in the civil engineering program determined an appropriate laboratory for this study, based on several key components. In producing this laboratory experiment, the researchers discussed experimental ideas that would encourage students to recognize and utilize concepts previously taught and apply that knowledge to the dynamic behavior of bridges specifically. Using concepts of free vibration and damage detection using dynamic parameters of bridge structures, the researchers consulted resources such as the first two chapters in Anil Chopra's Dynamics of Structures (2007) and Helmut Wenzel's Health Monitoring of Bridges (2009) to 
develop an introductory laboratory that would provide a challenging yet attainable procedure for a three-hour laboratory period. An ideal laboratory, as concluded by the researchers, would provide for a practical field scenario alternative, while incorporating assessment through laboratory experimentation. Following development of the framework of the laboratory and testing of various beam configurations, a cantilever beam was chosen for the configuration (Figures 3.1 and 3.2).

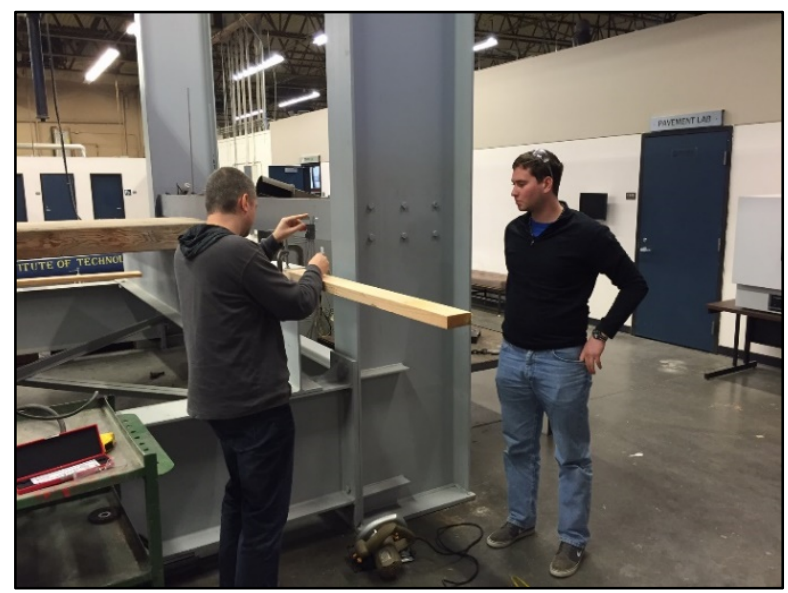

Figure 3.1: Students measure intentional section loss in laboratory structure

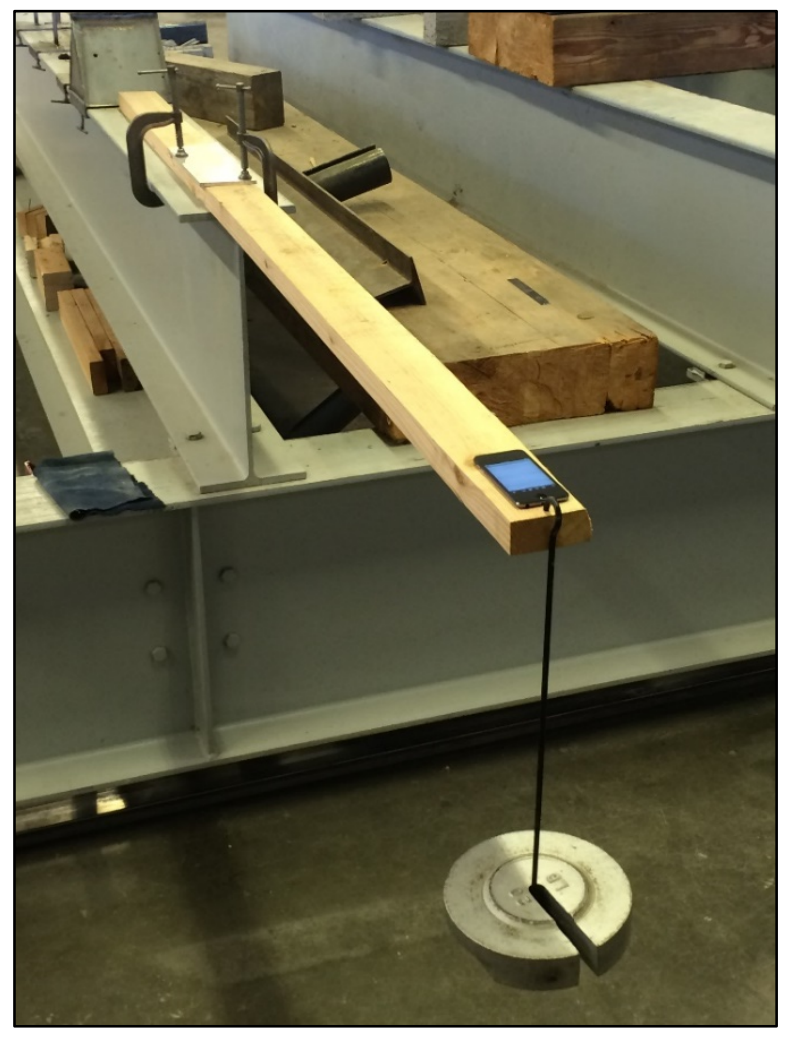

Figure 3.2: Tip-loaded cantilever used in laboratory module 
In order to determine the feasibility of utilizing iPods as a method of active learning for a structural dynamics laboratory, the investigators developed a laboratory module, conducted a laboratory experiment, and evaluated the learning gains and perceptions of three groups of students enrolled in the course. The student groups participated in the laboratory experiment independent of the other two groups, and all deliverables were completed and submitted independently. Student learning gains were then measured with a survey of students' perceived learning, as well as an evaluation of submitted lab reports. Using both indirect survey methods and direct laboratory memorandum evaluations, the investigators completed an analysis of the results and outlined conclusions regarding learning gains from the laboratory experiment. These conclusions are outlined further in the Conclusion section and Appendix A. 


\subsection{FINDINGS}

The development, implementation and assessment of laboratory modules using the grantsupported equipment produced findings related to curriculum development, laboratory module development and equipment used for education and research about structural health. These findings are elaborated below.

\subsection{CURRICULUM DEVELOPMENT}

While the curriculum development was not studied rigorously, anecdotal student feedback regarding the new equipment and expansion of program content into structural health and transportation structure evaluation was very positive. Because the concepts are introduced and reinforced in multiple undergraduate and graduate electives, students began to see the relevancy of the ideas and techniques as they applied in different venues.

\subsection{LABORATORY MODULE DEVELOPMENT}

Detailed findings from the direct and indirect assessment of the laboratory module can be found in the conference paper in Appendix A. In general, while learning gains appeared stronger for students who participated in the hands-on component of the laboratory, due to the small class size there were no statistically significant differences between using iPods in a hands-on laboratory versus a purely computational laboratory. However, students indicated that iPods and hands-on laboratories were their preferred experience. This study may be repeated in partnership with other universities to improve the sample size so that statistically significant results can be obtained.

\subsection{EQUIPMENT}

The iPods, SensorTags and shake table that now comprise the SHAKE Lab have proven to be valuable in courses beyond those originally anticipated. Preliminary work was conducted by the graduate students in the area of vehicle dynamics and roadway geometry and safety that resulted in NITC research and education funding for 2016-2017 to support further work in this area.

iPods and mobile devices in general, when employed to gather data, generate enthusiasm for the topic and are valuable for their relatively small expense, precise data, and ability to be handled by individual students. SensorTags, while not yet understood well enough to measure structural response, have potential for use in other laboratories and for field monitoring. They will be explored further and will likely be employed to monitor other values, like humidity, temperature and light.

The shake table, while used primarily for accelerometer evaluation in the context of this project, provides a useful platform for demonstration of scale-model structural response and will be featured in multiple elective courses in the future. It will also continue to be employed to compare the relative accuracy of dynamic evaluation methods. The researchers determined toward the end of this project that virtual visual sensors, essentially the pixel intensity in 
recorded video, can provide a simpler and more easily implemented means for evaluating the dynamic parameters of a structure. 


\subsection{DEVELOPMENT OF RESEARCH CAPACITY AT OREGON TECH}

\subsection{RESEARCH GOALS}

While this grant was primarily an education grant, the civil engineering department at Oregon Tech continues to develop its graduate program launched in 2013, and the initial proposal indicated that the grant would support development of a research program at the university. The equipment purchased has the potential to support both education and research, and has been used to its fullest potential. The grant has supported two graduate students during their master's work. The value of this support, both in terms of financial support and access to equipment, cannot be overstated. These students supported the curricular development with their unique perspectives and advanced the capabilities of our labs at the university. They also advanced their own knowledge and work in this area to the cutting edge of structural health monitoring.

The research team had specific goals for the equipment purchased and the faculty and student time funded by this grant. The iPods, with the potential for application identified prior to the grant, needed to be evaluated for precision and accuracy as acceleration sensors, and the potential to network the iPods to serve as sensors in a single/multiple input, multiple-output modal structural analysis needed to be evaluated. Other methods of doing this work inexpensively with application by state DOTs needed to be explored. And, the shake table, as a new piece of laboratory equipment, needed to be explored and tested for use in instructional laboratories and research support. The following sections will elaborate on these goals.

\subsection{1 iPods for Data Collection}

\subsubsection{Evaluation of iPods for use as acceleration sensors}

The impetus for this work was the observation by the project team that the accelerometers in mobile devices represented a widely available and possibly inexpensive method to collect acceleration data. Research-grade accelerometers and the precision that comes at great expense with these devices are perhaps not necessary for practical collection of data in the field. The team wanted to determine if this was the case.

\subsubsection{Evaluation of iPods for use in a wireless sensor network}

The potential of iPods to support dynamic evaluation of structures would be greatly improved if multiple iPods could be networked and their data aggregated to support a multiple-output approach to evaluation of a structure. Mode shapes could be observed and measured if this were the case. Certainly, iPods have the capacity to be networked in this way, but the team was uncertain if existing apps supported this functionality and what other software might need to be developed to functionalize this idea. The wireless communication available in iPods has the potential to simplify the implementation of a sensor network in the field, further supporting this idea. 


\subsubsection{Other Methods of Developing Acceleration Sensor Networks}

Wireless sensor networks are a very popular area of research. Identifying a convenient way of implementing a wireless sensor network, while maintaining necessary levels of precision, is the goal of many research groups around the world. In addition to considering an iPod sensor network, the team explored other options, both by purchasing equipment like the Texas Instruments SensorTags and via the literature. The virtual visual sensor, a method of recording video and evaluating changing intensity of pixels to determine dynamic response parameters, was being promoted by a colleague at PSU with the shared goal of measuring dynamic response cheaply and simply with necessary precision. The team also spent time with this method to explore its applicability.

\subsubsection{Shake Table Capabilities}

The Quanser Shake Table I-40 is intended to be a plug-and-play laboratory tool, but like any piece of equipment, it requires time to understand and use effectively. The grant support allowed the research team this time and opportunity. While the table has limitations that were not anticipated initially, it has proven to be a valuable addition to Oregon Tech's teaching and research toolbox.

\subsection{RESEARCH APPROACH}

The research component of this work was based on a literature review and remains in progress, with the primary focus of the funded work being the evaluation of the iPod accelerometers. Details of the literature review, sensor network feasibility assessments, and device and sensing method evaluations are provided.

\subsubsection{Literature Review}

The research team conducted a literature review of structural health monitoring methods, which is a broad and rapidly developing field. Specific challenges and developments in sensor networks are elaborated in numerous studies. Detailed approaches to wireless networking, field deployments, specific systems, and case studies abound (Wenzel, 2009).

The team discovered documentation of iPods used individually to measure dynamic response of high-mast light towers (Orai et al., 2015), but did not find literature related to sensor networks of iPods deployed on a single structure. iPods, as well as other mobile devices, have been evaluated by others for their ability to be used to measure mechanical oscillations (Hopfner et al., 2013). Certainly, mobile devices are being used to collect and analyze large datasets involving geospatial data of all kinds. Real-time traffic data in mapping apps is one example of this type of application.

Structural health monitoring deployments fall into several categories, as outlined by Webb et al. (2015):

- Anomaly detection (observing differences in results from multiple evaluations).

- Sensor deployment studies (documentation of a novel system or capability). 
- Model validation (comparison of sensor data to finite element or other analysis).

- Threshold check (sensors that register excessive strains, deformations or accelerations).

- Damage detection (determination of damage type, location and extent via sensors).

This categorization of deployments provides a basis for comparing other work identified in the literature and outlining future work by the research group. The graduate students working on this project have made progress in the areas of sensor deployment studies (determining the useful range of the iPod accelerometers), and model validation (comparing field measurements of a single-span bridge with the results of a detailed finite element model). Their goal has been to advance the state of the art and practice in damage detection, particularly for bridges that have endured a significant seismic event.

\subsection{2 iPod Sensor Network}

The first mobile sensor platform we explored for potential use was the $3^{\text {rd }}$ Generation iPod running the iSeismometer, Seismometer, Sensor Stream, or similar app with data logging and broadcasting functionality. Most apps of this kind have a broadcast option that uses UDP protocol capable of being delivered through a local area network using a wireless router connected to a computer running a Python script that receives the UDP packets and collects them into a single data file.

\subsubsection{SmartTag Sensor Network}

The second mobile sensor platform we explored for potential use was the Texas Instruments multistandard SensorTag 2.0. These devices use a CC2650 SimpleLink multistandard wireless microcontroller for Bluetooth remote control application (Texas Instruments, 2015). The device contains a suite of sensors including an IR temperature sensor, digital microphone, humidity sensor, altimeter/pressure sensor, magnetometer, and an InvenSense MPU-9250 nine-axis MEMS motion sensor. The MPU-9250 contains the SensorTag's accelerometer and gyroscope.

\subsubsection{Virtual Visual Sensors}

Virtual visual sensors are essentially pixels in a video. Variations in the intensity of pixels, especially those located at the edges of vibrating elements, can be used to determine the frequency of vibrations. This method was compared to iPod accelerometer results to examine accuracy and precision of both methods.

\subsection{5 iPod Accelerometer Evaluation}

The research team was most interested in determining the range of frequencies and amplitudes that could be accurately measured with the iPod accelerometers. The system was configured as shown in Figure 5.1 to conduct this work. 


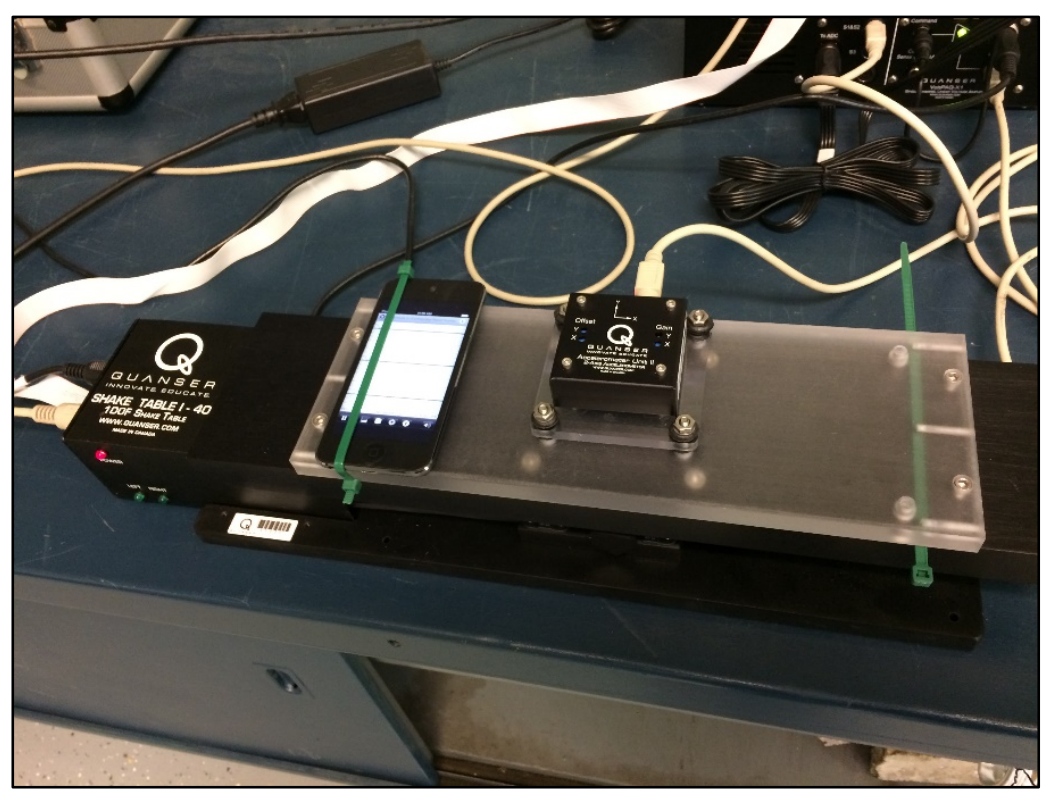

Figure 5.1: Quanser I-40 shake table with iPod and Quanser accelerometer

\subsection{RESEARCH METHODOLOGY}

\subsection{1 iPod Networking}

The project's original goal was to network a series of 12 iPods (all identical models) in a way that would allow for acceleration data to be read simultaneously from all 12 sensors on a single device. This would allow the team to collect data from different points on a single structure.

Staff in the university's information technology services department assisted in writing a Python script to receive a single iPod UDP data stream via WiFi to a computer hosting the network. The script was not capable of receiving and logging signals from multiple iPods. However, the potential for overcoming this challenge exists, and could be pursued in the future after identifying appropriate collaborators.

\subsection{2 iPod Accelerometer Evaluation}

\subsubsection{Test goals}

In order to determine the usable range of the iPod accelerometers, the research team conducted acceleration tests using the Quanser shake table to drive a single iPod at specified frequencies and amplitudes. In running these tests the team collected data simultaneously from the iPod and the Quanser accelerometer (part of the shake table system), both in order to provide confirmation of the shake table working at the specified frequency and amplitude and to set benchmark values to judge the iPod data against. The testing setup, shown in Figure 5.1, involves the Quanser accelerometer bolted to the shake table testing platform and the iPod attached to the platform in the same orientation using zip ties. 


\subsubsection{Data processing}

Both the Quanser accelerometer and the iSeismometer app output acceleration data in a .CSV file format, making it relatively easy to manipulate the data directly in Microsoft Excel. Unfortunately, as neither Quanser nor the iPods are capable of attaching accurate timestamp values to the exported data, timestamp values for each data point had to be added based on the sampling rate of the sensor. For these tests the Quanser accelerometer collected at a rate of 500 $\mathrm{Hz}$, while the iPod collected at a rate of $100 \mathrm{~Hz}$. Given that raw acceleration data alone contains numerous frequencies that can be identified, and that identification by visual means is prone to unacceptable amounts of human error, the team chose to use a fast Fourier transform (FFT) to identify the dominant frequency signal in each data set. For each test, if the dominant frequency identified by the FFT matches the frequency imposed by the shake table, then the sensor can accurately measure acceleration at that specific combination of frequency and amplitude.

The dominant frequency returned by the FFT is taken as the frequency corresponding to the maximum FFT magnitude value in the data. The returned values were of course not perfect and the accuracy of the FFT was based on a frequency tolerance range set around the forcing frequency from the shake table. For this set of tests the tolerance was set at $0.2 \mathrm{~Hz}$.

The team collected the results from each of the 66 tests conducted and partitioned the data for each sensor based on whether the returned FFT frequency fell within the $0.2 \mathrm{~Hz}$ tolerance. These test results, shown in Figures 5.2 and 5.3, show a rough graphical outline of the effective sensing range of the Quanser accelerometer and iPod.

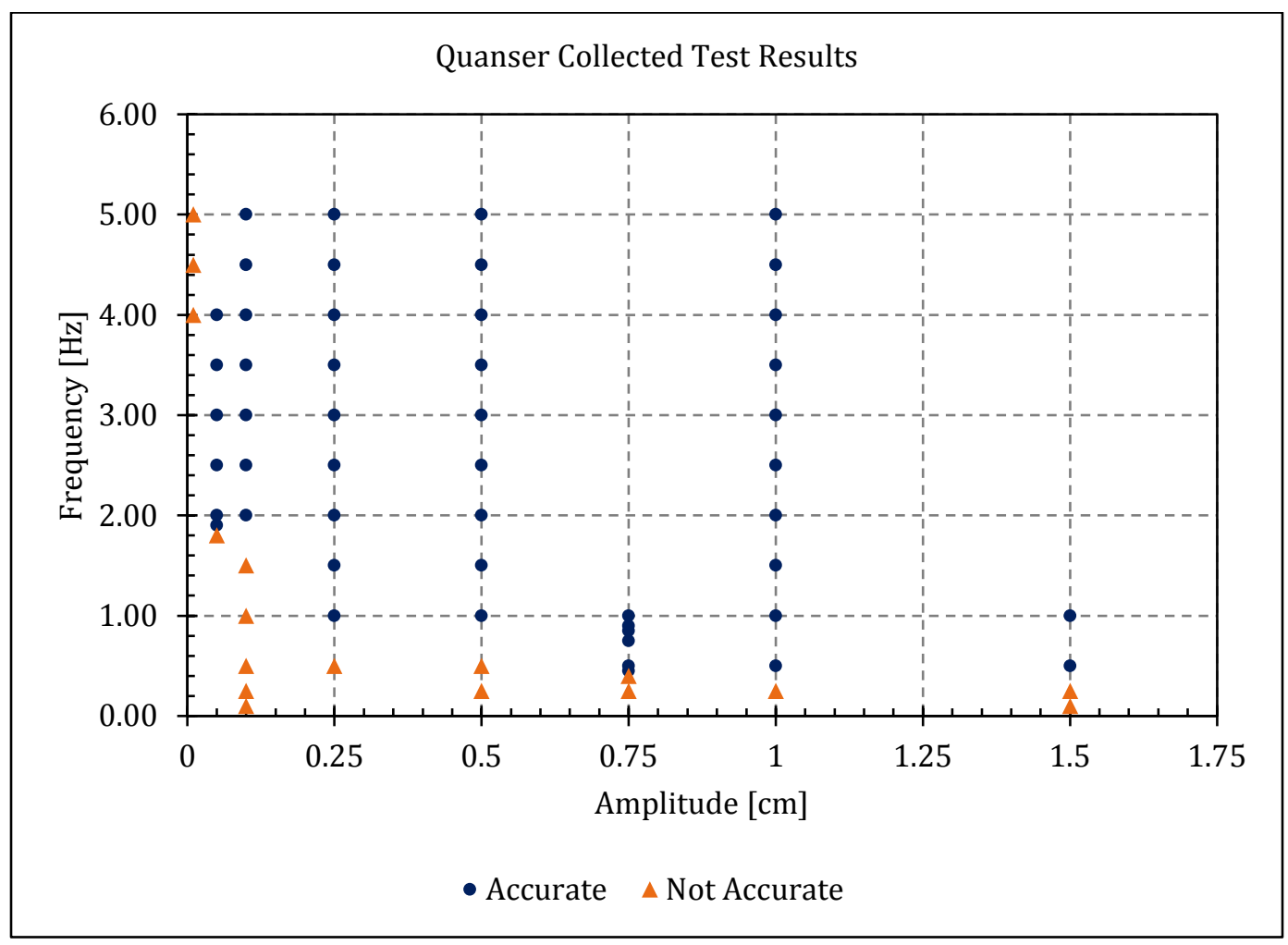


Figure 5.2: Results of accuracy evaluation of Quanser accelerometer

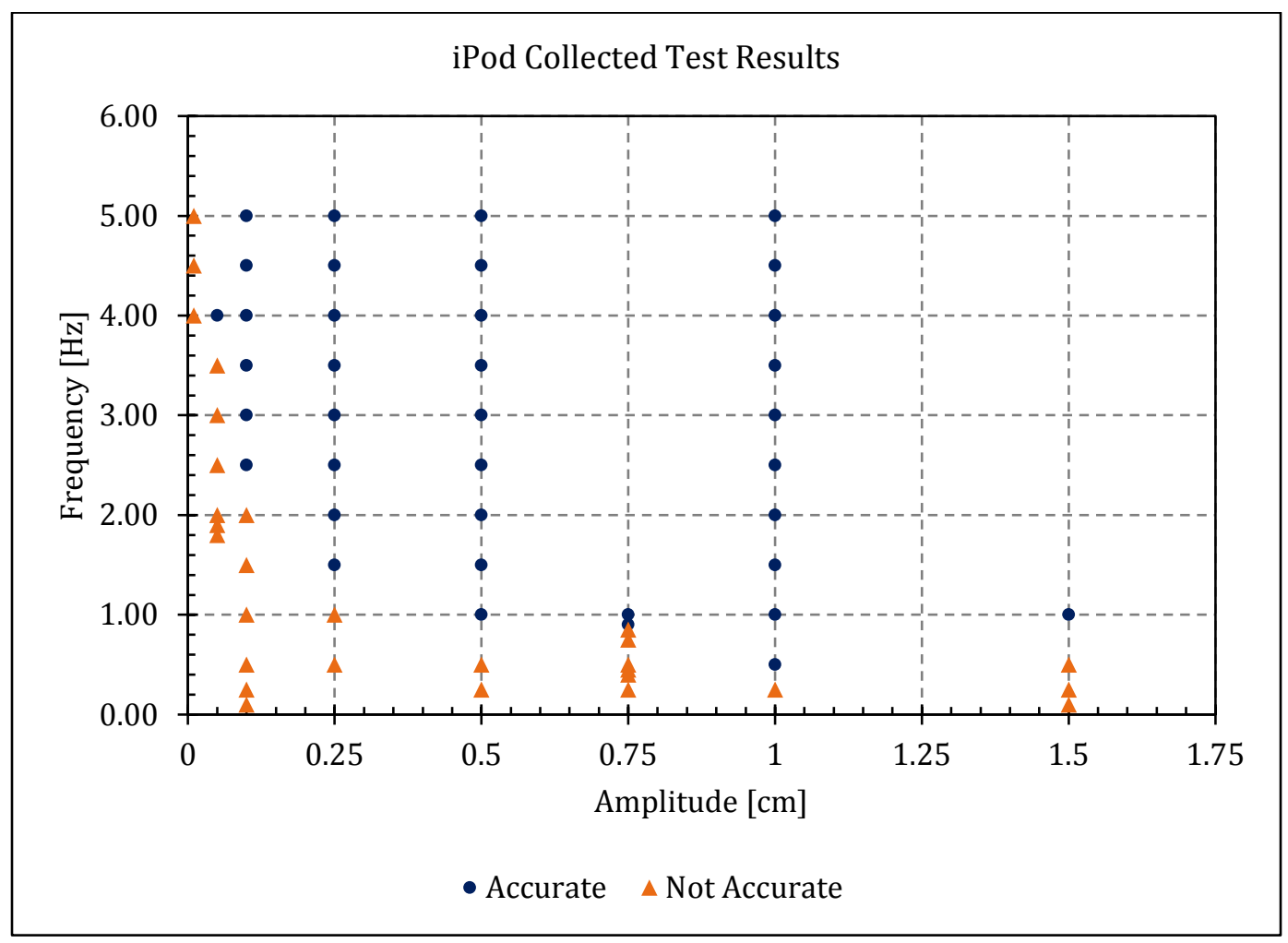

Figure 5.3: Results of accuracy evaluation of iPod accelerometer

By plotting the average difference between the accurate and inaccurate values, and fitting a regression line to the data, we were able to model an approximate limit line with frequency as a function of any given amplitude. Any point plotting below this line is considered to be outside of the reliably usable range of the sensor. A power series regression model was chosen to model the data as it better fit the data for lower amplitudes and higher frequencies, the area where most civil transportation structures lie.

An example of the data reduction process for the Quanser accelerometer tests is illustrated in Figure 5.4, where raw acceleration data is transformed into an FFT plot classified based on the ability of the FFT to identify the correct dominant frequency, and plotted against other tests to find the range limit of the sensor. 


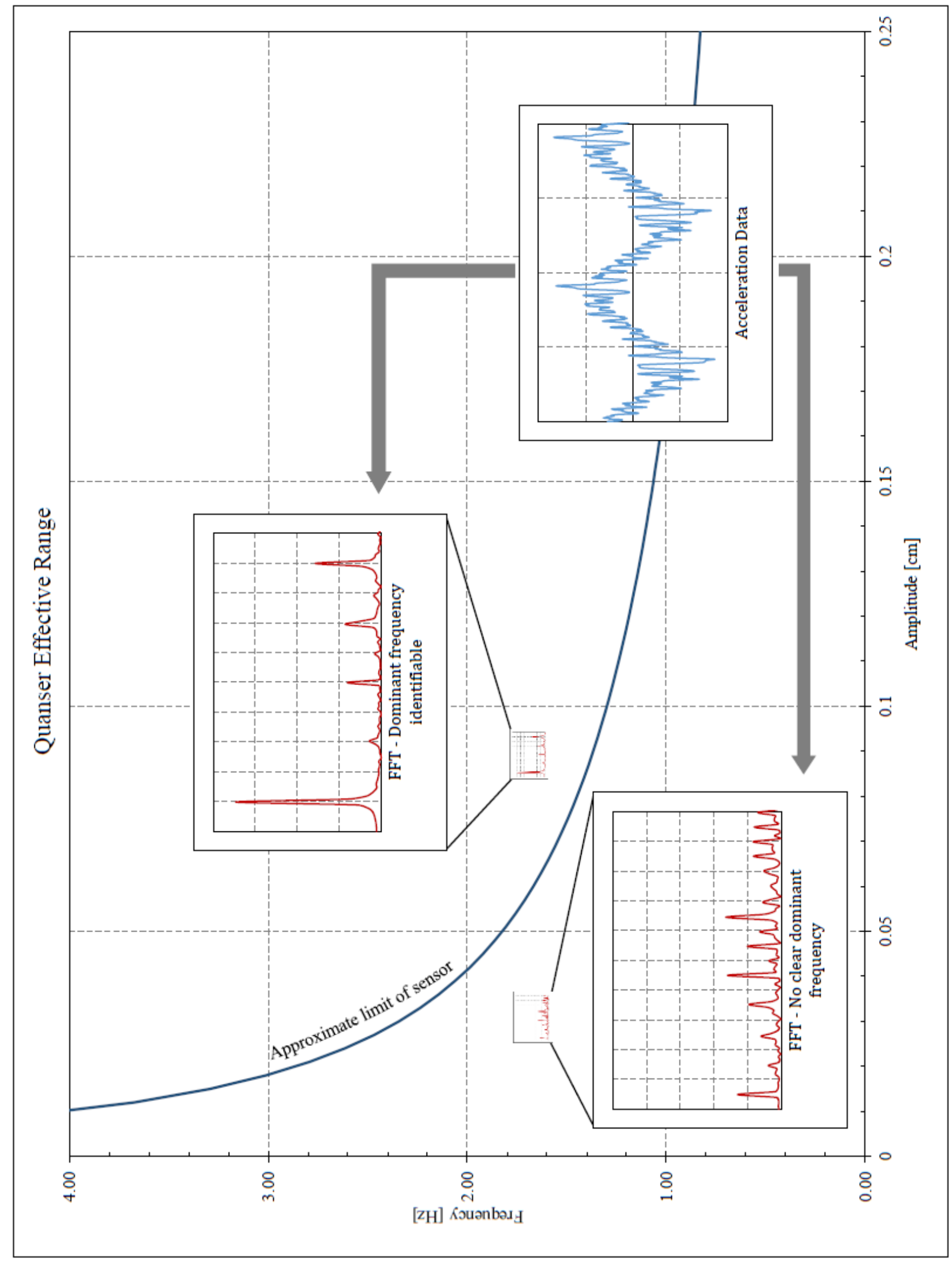

Figure 5.4: Summary of data reduction process used to determine accelerometer limits 


\subsubsection{SensorTag development}

The Texas Instruments SensorTag is an open source platform that allows for modification to the device software through the Bluetooth low-energy software stack program (BLE-STACK). Using BLE-STACK, and a development pack designed for use with the SensorTag, we attempted to modify the device to address several issues and create a sensor platform to collect data at a comparable precision to the iPod sensors. The three primary issues faced with using the SensorTags in their factory settings were:

1) The internal accelerometers read at a maximum sampling rate of $10 \mathrm{~Hz}$, too low for accurate measurements at most frequencies and completely out of the range of field use for many civil structures.

2) In order to conserve battery life the SensorTags automatically shut down and stop transmitting data after two minutes of operation. They then have to be restarted manually each time, making them impractical for long-term field use.

3) Like the iPods, the SensorTags are not set up to network back to a single device.

Given that the device software for the SensorTags is open source and freely available, we have confirmed with multiple software developers and from Texas Instruments that it is possible to change these settings. Technical specifications for the sensors indicate that the sampling rate can be adjusted up to $100 \mathrm{~Hz}$ (InvenSense, 2014), the same as the iPod sensors. Battery settings can also be adjusted using BLE-STACK, and a GUI to view sensor data from multiple SensorTags can be constructed using the BTool program within BLE-STACK.

While we have confirmed that these alterations to the device software are possible, the team has been less successful in implementing these changes. Issues related to the team members' own inexperience in software development, and our inability to find outside collaborators willing to assist with this work, have stalled development of the SensorTags for the time being. 


\subsection{RESEARCH FINDINGS}

iPods can effectively measure accelerations in transportation structures like bridges, sign structures and light poles; can generate valuable data; and can rapidly identify natural frequency if the app plots on the frequency spectrum (iSeismometer and Vibration apps). iPod sensor networks may be possible, but would require further collaboration with computer science faculty or professionals to develop code to gather broadcasted results and ensure sufficiently precise timestamping. Despite efforts to connect with computer science faculty at Oregon Tech, we could not identify willing collaborators.

There is potential for SensorTags to serve as an inexpensive sensor network, but sample rate limitations need to be overcome first. These limitations appear to be overcome on the software side of the device.

Results of the Quanser and iPod limit testing show that the iPod sensors are able to accurately measure acceleration at a similar range to the Quanser accelerometers. The resulting graph from the data processing, shown in Figure 5.5, displays the limits of both sensors as a power series regression model. This model also allows us to predict the sensor accuracy outside of the usable range of the shake table.

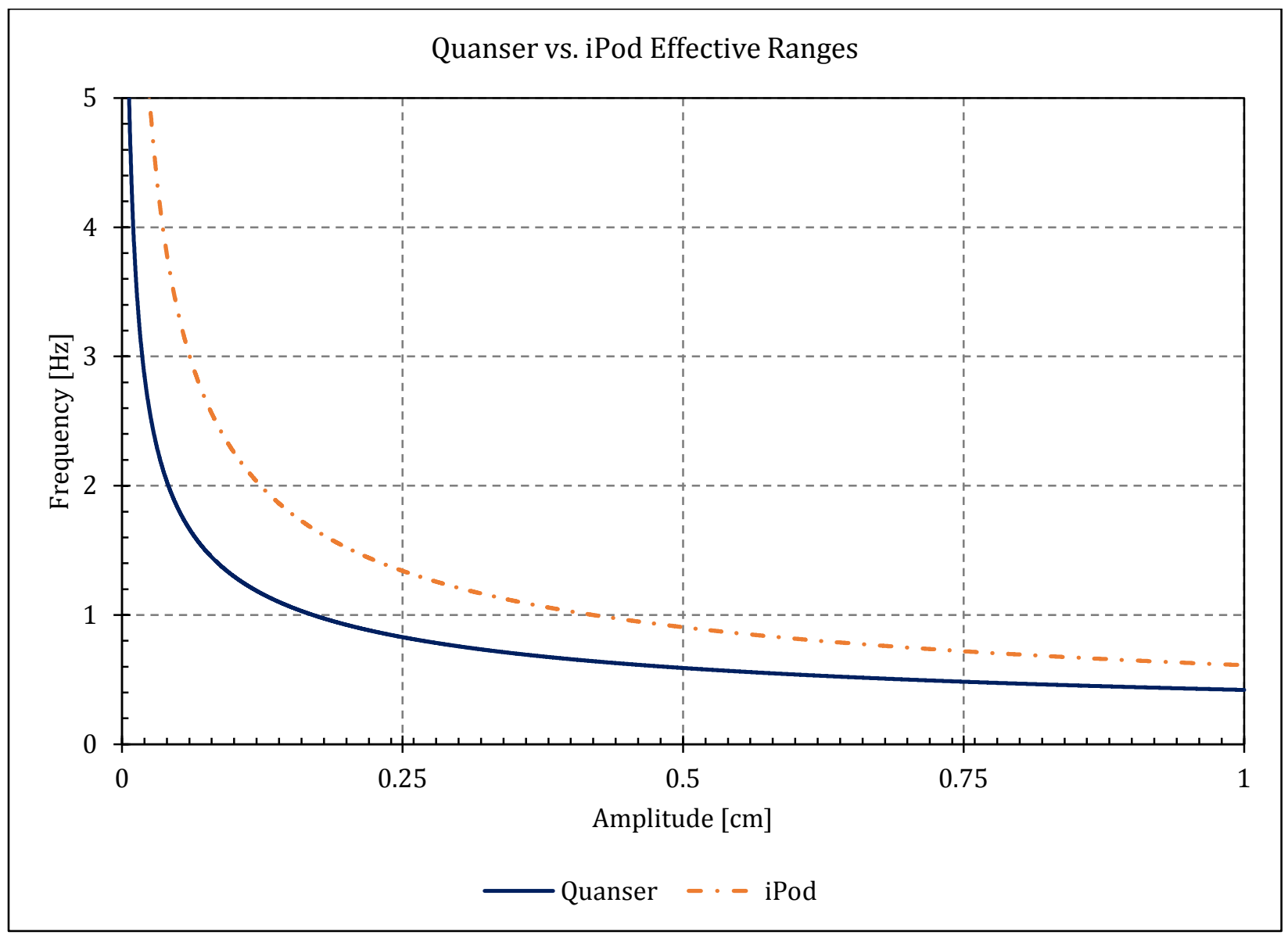

Figure 5.5: Comparison of limits of Quanser and iPod accelerometers 
The regression model equations and R-squared value for the data for Quanser and iPod sensors is shown in Equations 5.1 and 5.2, respectively.

$$
\begin{aligned}
& \text { Quanser: } \\
& \qquad \begin{array}{c}
\text { Frequency }=0.4198\left(\text { Amplitude }^{-0.49}\right) \\
R^{2}=0.9454 \\
\text { iPod: } \quad \text { Frequency }=0.6111 \text { (Amplitude }^{-0.567} \text { ) } \\
R^{2}=0.8232
\end{array}
\end{aligned}
$$

Limitations of these tests include the inability of the shake table to test at frequencies higher than $5 \mathrm{~Hz}$. We believe that the regression models allow us to approximate well the ability of the sensors to detect dominant frequencies outside of this range; it would make sense to conduct tests at frequencies of the structures we will likely be testing in the field. The team intends to conduct such tests using simple beams set up in the laboratory with known length and stiffness parameters to achieve these higher frequency tests. Additionally, the Quanser shake table software currently limits the number of data points that can be reported for any one test to 1,024 points. This many data points collected at $500 \mathrm{~Hz}$ leads to a maximum of approximately two seconds of data that can be collected for any test. Therefore, at frequencies lower than approximately $0.5 \mathrm{~Hz}$, the Quanser sensor is unable to plot a full natural period for the data. While the FFT is able to still identify some dominant frequencies without a full period of data, it is likely that the Quanser accelerometer is accurate to lower amplitudes and frequencies than our regression model shows. Taking this into account, we suspect that there is a more dramatic difference between the limits of the two different sensors than is shown in Figure 5.5, and portions of our future testing work will be devoted to increasing the reportable data range of the shake table and refining the regression model to reflect this.

Networking multiple iPods into a system was a much more challenging task, and is not currently complete. Further collaboration with computer science faculty and/or professionals would be needed to truly develop an iPod sensor network for field use. Due to these difficulties, and our inability to find collaborators within the university to assist in this matter, we have decided not to pursue development of an iPod sensor network any further. Our results show potential for such a network to be successful, but the effort required is beyond the resources available at Oregon Tech. 


\subsection{CONCLUSIONS}

\subsection{EDUCATION PROJECT CONCLUSIONS}

\subsubsection{Curriculum Development}

Development of the undergraduate and graduate curricula to include structural dynamics and health monitoring concepts, especially as they pertain to transportation structures, is a critical step in preparing students for professional practice in a world where many pieces of critical civil infrastructure are reaching the end of their design lives. The courses and laboratory experiences supported by this grant will continue to serve the students at Oregon Tech for years to come as they serve society as part of the solution.

\subsubsection{Laboratory Module}

Overall, the student response to this laboratory was positive, and the demonstration of learning gains was both perceptible by the students through self-reporting and demonstrated by the students in their laboratory report submissions. As an introductory module, the laboratory experiment has the benefit of simulating a significant real-world problem (structural deterioration and damage detection) as well as providing a platform for comparing theoretical and experimental results.

The use of devices was widely regarded as a positive aspect of this laboratory. As a result of this study, the instructor will continue developing laboratories that employ mobile devices like smartphones and iPods to gather data. Students expressed interest in exploring their curiosities as a result of learning about the capability of their devices. While it seems logical that greater learning can result from asking questions and having good tools with which to measure, students may not be aware of the power of the devices they have in their pockets.

\subsection{RESEARCH DEVELOPMENT CONCLUSIONS}

iPods have potential use in the field, if software side challenges are overcome. Individual iPod use in the field currently has much more potential, is more developed and documented, and has recent publications supporting the application.

SensorTags have potential for use in the field, similarly if software side challenges are overcome. They are an effective and inexpensive platform for gathering acceleration data. Once default sample rates can be increased, higher-frequency vibrations can be measured. Networking of these devices appears to be easier and better supported than currently published iPod apps. These units also have the benefit of being much less expensive than iPods ( $\$ 30$ vs $\$ 200$ ).

Virtual visual sensors have more promise for field applications than iPod or SensorTag sensor networks. They can potentially be implemented for the price of a camera. The algorithm is developed and is relatively simple, but could be commercialized. This area is ripe for continued applied research, and appears to be the best approach for developing an inexpensive and effective transportation-structure dynamic evaluation method. 
In order to pursue this work further, the research team needs to evaluate forcing methods like linear shakers or drop hammers. 


\subsection{FUTURE WORK}

\subsection{EDUCATION}

The research assistants are in their final year of work on this project. New students are already in the pipeline to continue this work. More than likely, the process of refining and revising curriculum will fall to the PI, while student research will be the goal of ongoing work with this equipment.

Work will continue that supported both the education and research elements of this project related to the shake table. Specifically, limitations of the Quanser software that controls the shake table and records data only up to 1,024 points will be overcome by learning more about using Matlab’s Simulink Coder to control the table and record more results.

The shake table, iPods and SensorTags will be incorporated into more courses to further develop our hands-on approach to learning.

\subsection{RESEARCH}

Follow-up research in the area of structural dynamics and structural health monitoring is already underway, supported by a NITC research grant (\#1022). Additional work to study vehicle dynamics is also underway using the iPods and supported by another NITC education grant (\#1073). Future work in the area of structural dynamics will be outlined below from immediate to long term.

Research assistants are exploring the precision of virtual visual sensors at various amplitudes and frequencies of vibration and for their ability to measure the magnitude of displacements. They are also exploring means of forcing bridge structures using drop masses and actively controlled linear shakers. A linear shaker has been purchased and will be brought online in the winter of 2017. At the same time, a trailer-mounted, drop-mass system will be developed to excite bridge structures using impact loading.

One graduate student is examining the field implementation of virtual visual sensors on a local short-span, steel-girder bridge. The student will conduct a finite element model validation to identify dynamic response parameters numerically for comparison to field measurements.

The potential exists to implement virtual visual sensors via drone-mounted video recordings. Laboratory testing will be conducted to determine if drone vibrations introduce excessive noise and render the virtual visual sensors useless or if this noise can be filtered. The frequency of a drone may be sufficiently far from the frequency of a structure being measured, rendering this a moot point. 


\subsection{REFERENCES}

Chopra, Anil. Dynamics of Structures, 2nd Ed. New Jersey: Pearson Prentice Hall. 2007.

Feisel, Lyle D., and Albert J. Rosa. "The Role of the Laboratory in Undergraduate Engineering Education." Journal of Engineeing Education 121-130. 2005.

Estes, Allen C., Ronald W. Welch, and Stephen J. Ressler. “The ExCEEd Teaching Model”. Journal of Professional Issues in Engineering Education and Practice. ASCE. 2005.

FHWA. Long-Term Bridge Performance Program (LTBP), accessed December 31, 2016. https://www.fhwa.dot.gov/research/tfhrc/programs/infrastructure/structures/ltbp/about.cfm

Herrington, J., A. Herrington, J. Mantei, I. Olney, and B. Ferry. "Using mobile technologies to develop new ways of teaching and learning." Murdoch Research Repository (Murdoch Research Repository) 1-14. 2009.

Hopfner, Hagen, Guido Morgenthal, Maximilian Schirmer, Marcel Naujoks, and Christoph Halang. "On Measuring Mechanical Oscillations using Smartphone Sensors - Possibilities and Limitation." ACM SIGMOBILE Mobile Computing and Communications Review 1-11. 2013.

InvenSense. “MPU-9250 Product Specification Revision 1.1”. InvenSense Incorporated. 2014.

Orai N, Ichii K, Ishii S. A trial of simple and easy health monitoring for power poles by using ‘ipod’. Science China Technological Sciences. 2015.

Prince, Michael. “Does Active Learning Work? A Review of the Literature.” Journal of Engineering Education. ASEE. 2004.

Prince, Michael J., and Richard M. Felder. "Inductive Teaching and Learning Methods: Definitions, Comparisons, and Research Bases." Journal of Engineering Education 123-138. 2006.

Texas Instruments. “Multi-Standard CC2650 SensorTag Design Guide”. Texas Instruments Incorporated. 2015.

UCIST University Consortium on Instructional Shake Tables

https://engineering.purdue.edu/UCIST/. Accessed December 15, 2016.

Wenzel, Helmut. Health Monitoring of Bridges. Hoboken, NJ: Wiley. 2009.

Work, Daniel B., and Alexandre M. Bayen. "Impacts of the Mobile Internet on Transportation Cyberphysical Systems: Traffic Monitoring using Smartphones." National Workshop for Research on High-Confidence Transportation Cyber-Physical Systems: Automotive, Aviation and Rail. 2008. 


\subsection{APPENDIX A}

ASEE PAPER 2016

\section{POSTERS}




\title{
Available at: https://www.asee.org/public/conferences/64/papers/15415/view
}

\section{Using Mobile Devices to Teach Structural Dynamics and Structural Health Monitoring}

\author{
Dr. Charles Riley, P.E., Oregon Institute of Technology \\ Jason D. Millar, Oregon Institute of Technology \\ Samuel Lozano, Oregon Institute of Technology \\ Dr. Sean St.Clair, P.E., Oregon Institute of Technology
}

\begin{abstract}
This paper studies the effect of using mobile devices to teach topics in structural dynamics and structural health monitoring (SHM). Devices, like iPods and smartphones, running apps that record accelerometer data are increasingly common in the classroom and are more available to instructors. Given that structural dynamics and SHM are commonly advanced courses or research topics, the goal of this work was to create and evaluate a module that employs increasingly commonplace mobile devices to actively engage students in these topics and to generate enthusiasm for further study in structural dynamics and structural health topics like damage detection in engineered structures. Assessment of student laboratory reports for demonstration of stated learning objectives and student survey results are presented.
\end{abstract}

\section{Introduction}

While there is plenty of discussion about technology in the classroom, exposing students to cutting-edge approaches to structural health monitoring using familiar devices may have a positive influence on learning in a laboratory session. Creating laboratory procedures to simulate practical field scenarios increases the inherent connection between education and practical experience. The purpose of this paper is to document the research and analysis performed on an introductory laboratory session for structural dynamics with an emphasis on structural health monitoring. The primary research questions tested with this study are:

- Do devices in the classroom foster enthusiasm for the topic?

- If devices are used by a group of students, does this have an impact on learning?

- Does the hands-on nature of the laboratory matter? Or, is data analysis and calculation sufficient? Is direct instruction even necessary?

In order to test these questions, a group at Oregon Institute of Technology prepared a laboratory module, conducted a laboratory experiment and evaluated the learning gains and perceptions of three groups of students using a performance-based survey as well as evaluation of student lab reports.

In a structural dynamics laboratory setting, three alternative delivery methods were used as a basis for the study. The students were divided into three groups prior to participating in the laboratory experiment. The first group consisted of graduate students in a hands-on laboratory setting (the "Experiment” group). The second group consisted of undergraduate students in a purely computational laboratory (the "No experiment" group), using the data collected from the hands-on laboratory to complete the analysis portion of the assignment. Finally, the third group 
consisted of senior and graduate students who had traveled to Washington, D.C., for the Transportation Research Board convention during the assigned laboratory session. This third group of students (the "No lab" group) received only the data collected and a description of the laboratory, simulating an online-course delivery style.

This paper provides a summary of current studies and observations directly corresponding to the research questions outlined above; an in-depth description of the laboratory module development; specific conduct of each laboratory section; a summary of the laboratory experiment procedure; and results of the assessments utilized with a discussion of implications. The laboratory module effectively follows Feisel and Rosa's Fundamental Objectives of Engineering Instructional Laboratories for the "Experiment" group, but provides less emphasis on senses in the "No experiment" and "No lab" versions" ${ }^{2}$. The materials, handouts and instruction for each laboratory session are located in the corresponding appendices. In assessing student responses in each laboratory section, the researchers analyzed survey responses and manually assessed the written responses for demonstration of learning objectives. Following the laboratory development and conduct and analysis of survey results, this paper will discuss the conclusions gathered from this study with respect to the research questions above.

According to recent research in alternative teaching and learning practices in science and engineering courses, students seem to respond more positively to inductive or active learning when compared with traditional lecture sessions ${ }^{6}$. The purpose of this study is to evaluate the effect of mobile devices as experimental tools in an active learning environment for courses in structural dynamics and structural health monitoring. In the context of this study, alternative teaching practices refer to non-traditional methods of instruction, including active, inductive and problem-based learning (PBL). In this study, the use of mobile devices in the classroom was intended for the purposes of data collection and clarifying the quantities measured. Active learning with the use of personal mobile devices is a relatively modern and sometimes controversial topic that often receives outstanding support or determined opposition in the field of engineering and related fields.

The wide use and acceptance of technology in the classroom provides an opportunity for students to interact more efficiently with information and peers in a learning environment. The interactive teaching methods discussed in this paper relate to active, inductive and PBL. Active learning is most generally defined as any instructional method of engaging students for the entire duration of the teaching contact time ${ }^{6}$. In addition to traditional homework and examinations, active learning allows students to participate in collaborative activities that positively influence student attitudes and study habits for course material ${ }^{6}$. Inductive learning encompasses interactive instruction techniques including inquiry learning, PBL, project-based learning, case-based teaching, and discovery learning ${ }^{5}$. PBL incorporates relevant problems introduced at the beginning of instruction to provide context and motivation for the learning that remains ${ }^{6}$. In response to recent research involving the introduction and use of alternative learning in the classroom, studies suggest that "students will retain information longer and perhaps develop enhanced critical thinking and problem-solving skills,” if active learning methods are employed ${ }^{6}$.

The use of devices in the classroom affects the perception of material by using relatable and convenient tools in a practical application. When used as a tool for active learning, such as data 
collection and analysis, rather than for low-level communication or recording, mobile device technology has the ability to foster the amplification, extension, reconstruction and reorganization of knowledge in an interactive learning environment ${ }^{3}$. Using devices in an active learning environment encourages a greater level of critical thinking and problem solving that supports good practice in engineering laboratories ${ }^{2,3}$.

Precise data collection in the engineering field requires reliable and consistent results available in a laboratory, as well as in field scenarios. Utilizing mobile devices and smartphones to collect and measure data encourages students to experience the reality of engineering measurement with the ease of convenient collection technology. Although the utilization of smartphone data collection is a relatively recent concept for structural dynamics and structural health monitoring, mobile devices have been and are currently in use as monitoring systems for transportation structures $^{4}$. Researchers from Nokia Research Center Palo Alto, Navteq and UC Berkeley conducted an experiment known as Mobile Millennium involving the implementation of a stateof-the-art mobile phone GPS data collection system to monitor traffic conditions and real-time traffic estimation $^{8}$. Following the experiment, researchers found that developing this mobile application would allow for the successful collection, analysis and reporting of traffic condition estimates $^{8}$. As in the use of GPS data for traffic condition estimation, the accelerometer component and iSeismometer application provided in modern mobile devices have significant potential for damage detection and estimation of structural health in the field of structural engineering.

\section{Module Development}

Drawing from concepts in structural dynamics and structural health monitoring, the structural engineering instructor and two graduate students in the civil engineering program determined an appropriate laboratory for this study, based on several key components. In producing this laboratory experiment, the researchers discussed experimental ideas that would encourage students to recognize and utilize concepts previously taught, and apply that knowledge to the dynamic behavior of bridges specifically. Using concepts of free vibration and damage detection using dynamic parameters of bridge structures, the researchers consulted resources, such as the first two chapters in Chopra's Dynamics of Structures and Wenzel's Health Monitoring of Bridges, to develop an introductory laboratory that would provide a challenging yet attainable procedure for a three-hour laboratory period $^{1,7}$. An ideal laboratory, as concluded by the researchers, would provide for a practical field-scenario alternative, while incorporating assessment through laboratory experimentation. Following development of the framework of the laboratory and testing of various beam configurations, a cantilever beam was chosen for the configuration, as depicted in the corresponding sections below.

Dividing the students into three groups allowed for the analysis of student perceptions as a result of an active learning technique, computation-only environment, or an online course-based delivery style. In order to assess and examine the performance criteria pertinent for the given research objectives, the researchers defined the laboratory report requirements and developed a group-specific survey. These chosen criteria were based on the most relevant aspects of this laboratory experiment: the study of devices used as a data collection tools and alternative teaching techniques for each section. 
After students completed the laboratory report and survey, the results were evaluated and analyzed by the researchers. These responses were analyzed and reported in the paper based on average ratings specific to each section. Using the submitted reports and surveys, the researchers assessed performance ratings from students to attempt to answer the research questions outlined above.

\section{Conduct of the Laboratory Sections}

The 19-student class was broken into three sections. The two students involved in developing the module participated in different sections, but did not take the assessment survey and are not included in the results.

For the two in-lab sections, the laboratory period began with an orientation to the topic and review of the laboratory handout (see Appendix) and procedure. The following learning objectives were used to structure the delivery and evaluate learning:

1. Identify the natural frequency and period of a freely vibrating single degree-of-freedom (SDF) system using:

a. Measurement of free vibration with an initial displacement and

b. Calculation with system stiffness and mass parameters.

2. Identify the damping ratio of a freely vibrating SDF system by supplying an initial displacement and analyzing the log decrement of the measured response.

3. Describe the effect of mass and stiffness on the natural frequency and natural period of a SDF system.

4. Describe the parameters that affect the damping ratio of a structure.

5. Analyze dynamic response data to determine the natural period and damping ratio of a structure.

6. Evaluate the ability of multiple dynamic evaluations to identify damage in a structure.

The laboratory sections consisted of the following groups:

1. "No experiment" - The group of seven students who attended the laboratory and participated in the pre-lab lecture and in-lab data analysis, but did not conduct the experiment. These students did not touch the experimental apparatus physically and encountered it only as a 2D drawing and verbal description.

2. "Experiment" - The group of seven students who attended the laboratory, participated in the pre-lab lecture, physically tested the tip-loaded cantilever, and conducted in-lab data analysis. These students participated in the complete experience.

3. "No lab" - The group of three students who were not able to attend the laboratory and completed it using the materials provided electronically along with a short description of what they missed in the laboratory and details involved in the data analysis. These students had an experience similar to online instruction. No video of the professor nor photographs of the apparatus were provided. 


\section{Laboratory Experiment}

The laboratory experiment, conducted by the "Experiment" students, employed an 8-foot Douglas Fir Larch Standard grade 2x4, set up as a 4-foot-long cantilever beam. It was clamped to a testing frame with C-clamps and oriented to bend about the minor axis (Figure 1). On the free end, a 20-pound weight was hung to serve as a concentrated mass. An iPod loaded with the iSeismometer app was placed on top of the free end to collect acceleration response data. Due to the relatively long period and low frequency of the beam in this configuration, there was no need to clamp the iPod to the member to ensure good test data. Once the test was properly set up, the beam was displaced by hand at the free end and allowed to oscillate while acceleration response data was collected in the $\mathrm{Z}$ (vertical) axis.

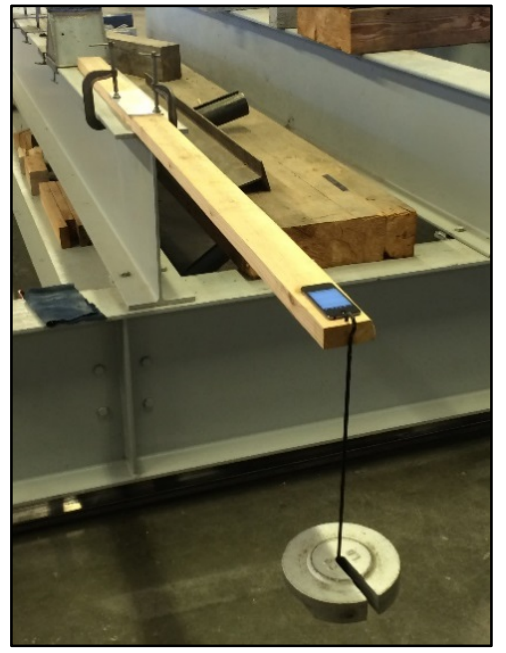

(a)

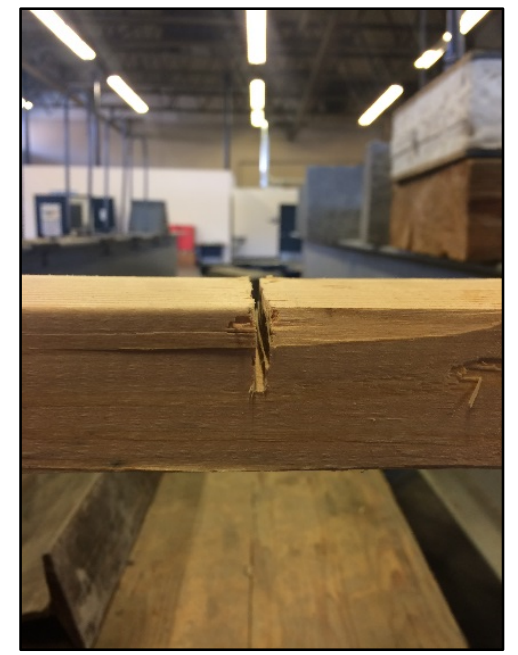

(b)

Figure 1. Test configuration (a) and 50\% section loss in the beam (b)

Three test scenarios were conducted with different amounts of section loss inflicted using a circular saw to simulate long-term damage to the beam, one with the full section, one with $25 \%$ damage, and one with 50\% damage (Figure 1b).

After each test was complete, the raw data was exported directly to an Excel spreadsheet by the iSeismometer app. Acceleration data was plotted with respect to time and used to find the natural period and damping ratio of the system. From the natural period other dynamic parameters were calculated, including circular and cyclic natural frequency.

The dynamic parameters of the natural period and damping ratio were plotted against the percent section loss of the member, and students were asked if they could identify any correlation between the damage induced in the beam and its dynamic response.

As part of the exercise, students were asked to confirm the physical properties of the beam and use them in subsequent calculations before beginning the test. These values were used to calculate the stiffness of the beam and confirm analytically that the natural period of the system, measured by experimentation, was correct. 


\section{Assessment}

Assessment of learning was based on (1) instructor evaluation of student laboratory memoranda following the laboratory and (2) student perception of learning gains (via survey). Each assessment was conducted according to the learning objectives stated in the Conduct of the Laboratory Sections section above and repeated here for convenience.

1. Identify the natural frequency and period of a freely vibrating single degree-of-freedom (SDF) system using

a. Measurement of free vibration with an initial displacement and

b. Calculation with system stiffness and mass parameters.

2. Identify the damping ratio of a freely vibrating SDF system by supplying an initial displacement and analyzing the log decrement of the measured response.

3. Describe the effect of mass and stiffness on the natural frequency and natural period of a SDF system.

4. Describe the parameters that affect the damping ratio of a structure.

5. Analyze dynamic response data to determine the natural period and damping ratio of a structure.

6. Evaluate the ability of multiple dynamic evaluations to identify damage in a structure.

\section{Instructor Evaluation of Student Laboratory Memoranda}

Levels of achievement for each learning objective were used for grading the memorandum format reports submitted by students. Each learning objective was scored on a scale from high (4) to low (2) proficiency, with the absence of demonstration scored lowest (1) (Figure 2).

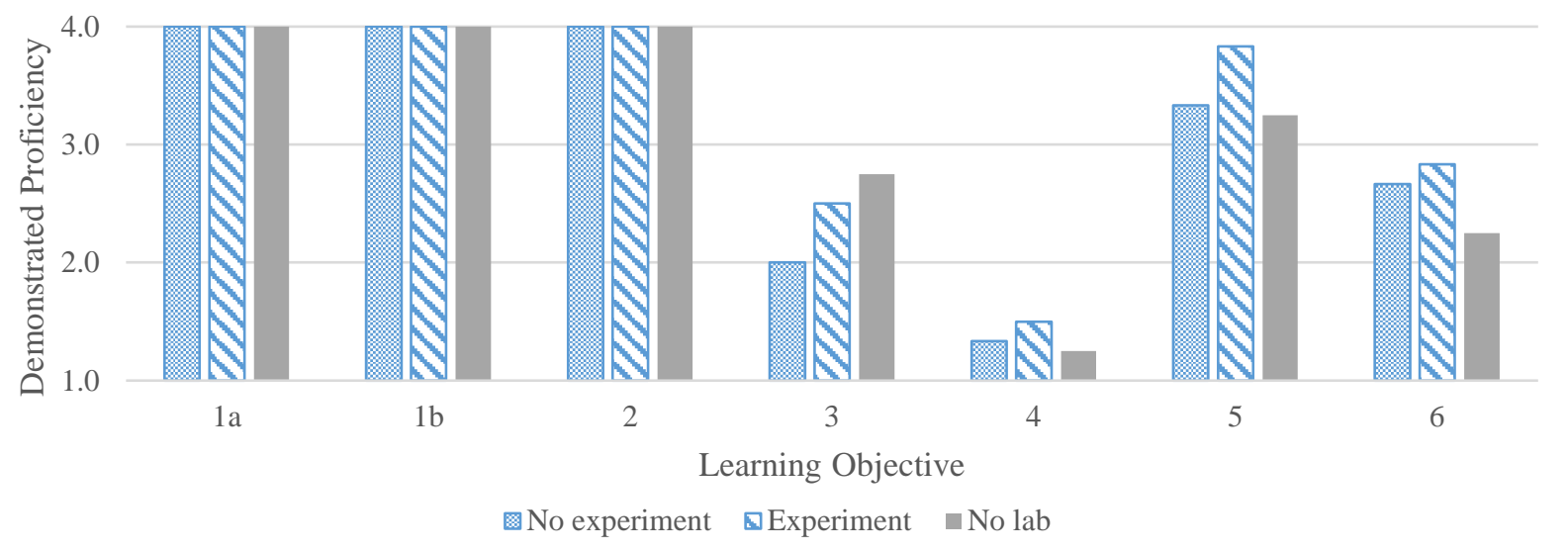

Figure 2. Average demonstrated proficiency per learning objective for each lab section

The first two learning objectives were essentially completed during the laboratory and available for checking by the instructor. All students included the results in their report. Scoring of the last four learning objectives was based on written descriptions provided by the students. Without more students in each section, these results do not provide conclusive evidence that the laboratory section influenced student proficiency as demonstrated by their report. Variations appeared to be correlated more with a given student's usual degree of effort on assignments like this than their understanding. Stated differently, some students did not write enough to evaluate their understanding of the learning objectives. 
While many students noted that increases in the natural period were demonstrated due to reduced stiffness resulting from the inflicted damage, not all of them clearly articulated this conclusion. Damping ratio was more variable and results depended on the values students selected to calculate the damping ratio. Most students attributed this variability to error and declined to comment further on the expected trend. However, all students concluded that the damping ratio is less influenced by damage than the natural period.

There was wide variability in the responses based on learning objective six (Evaluate the ability of multiple dynamic evaluations to identify damage in a structure). Regardless of graduate or undergraduate student status, some students used the opportunity to explore, deeply in some cases, the challenges and potential benefits of structural health evaluation using dynamic properties, while others indicated that the challenges were likely too great and the problem was essentially intractable. It was these latter students who wrote the least.

\section{Student Perception of Learning Gains, Use of Technology, and Conduct of Laboratory}

After completing their laboratory reports, students participated in a survey and rated their ability to do the things indicated in each learning objective on a 4-point scale from "poor (1)" to "fair (2)” to "good (3)" to "excellent (4)." "Not sure” was also included as an option but was not selected by any student. Student self-reported abilities to do what is described in the learning objectives before and after the laboratory are provided per group in Figures 3 (No experiment), 4 (Experiment) and 5 (No lab). In general, the "No experiment" section indicated that they had greater proficiency in the learning objectives initially. Learning gains are shown in Figure 6.

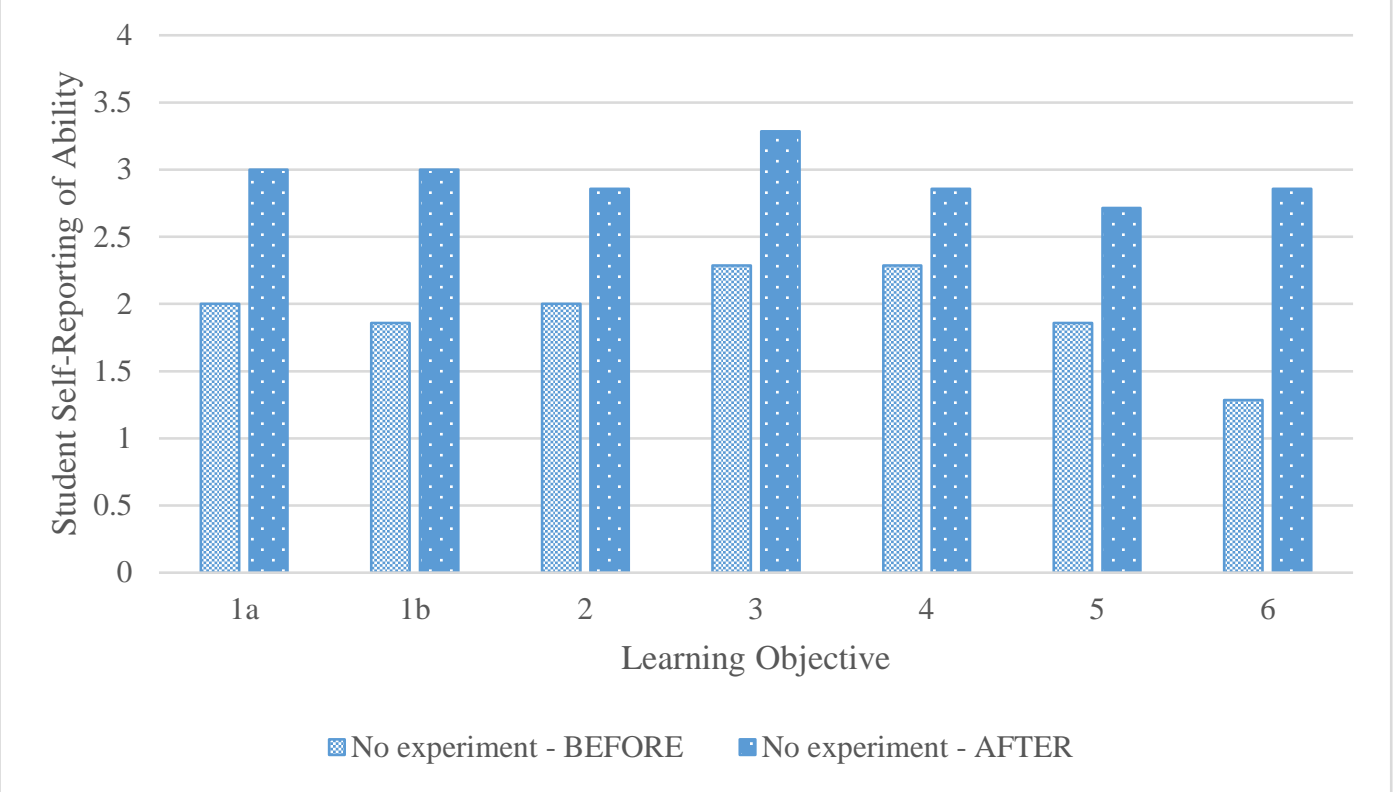

Figure 3. Self-reported abilities of students for each learning objective before and after the "No experiment” laboratory section 


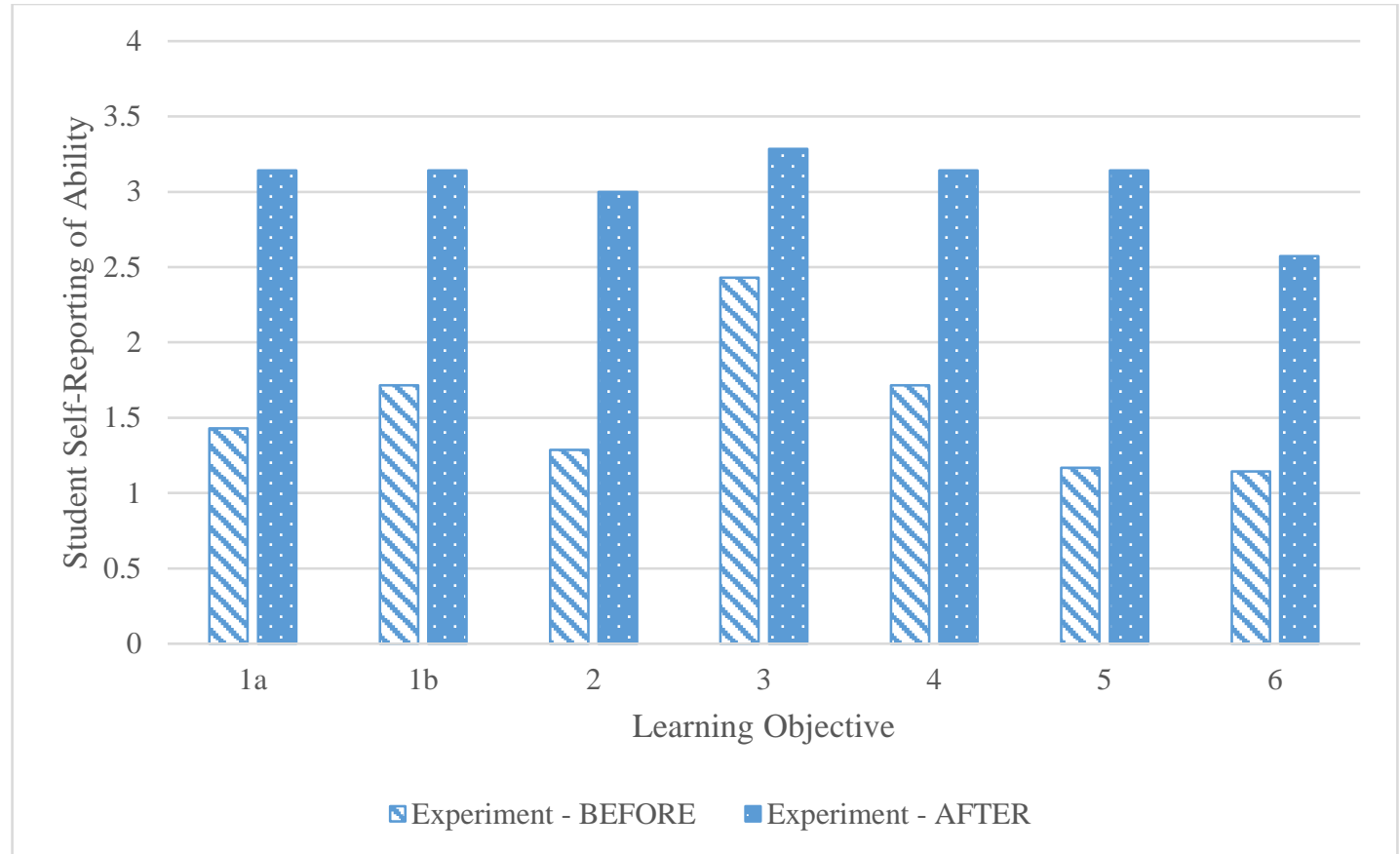

Figure 4. Self-reported abilities of students for each learning objective before and after the "Experiment” laboratory section

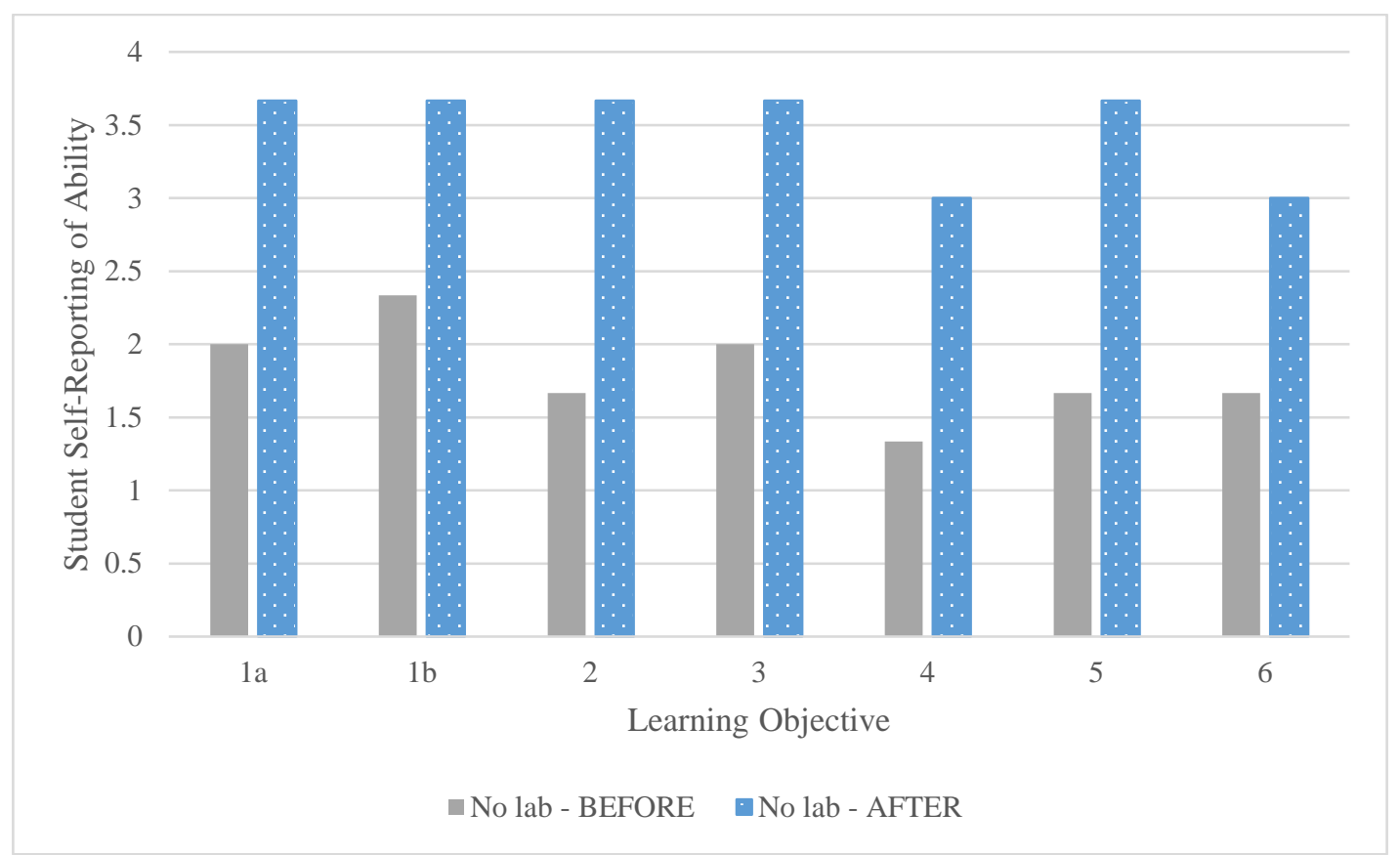

Figure 5. Self-reported abilities of students for each learning objective before and after the "No lab” laboratory section

The average learning gain for each laboratory section is summarized in Figure 6. The total average learning gain reported by the "No experiment" section was 1.00, while the average learning gain reported by the "Experiment" section was 1.53 and 1.67 for the "No lab" section. Students in the "Experiment" section self-reported greater learning gains for each learning 
objective except (3) Describe the effect of mass and stiffness on the natural frequency and natural period of a SDF system and (6) Evaluate the ability of multiple dynamic evaluations to identify damage in a structure. This may be the result of more discussion of this topic in the "No experiment" section. This discussion was prompted by student questions, likely as a result of not having a physical experiment to review. However, this discussion may have contributed to greater actual or perceived gains by the "No experiment" group. The greater differences in learning gains for the "Experiment" and "No experiment" sections for the other learning objectives provide some evidence that the hands-on, experimental approach was more effective.

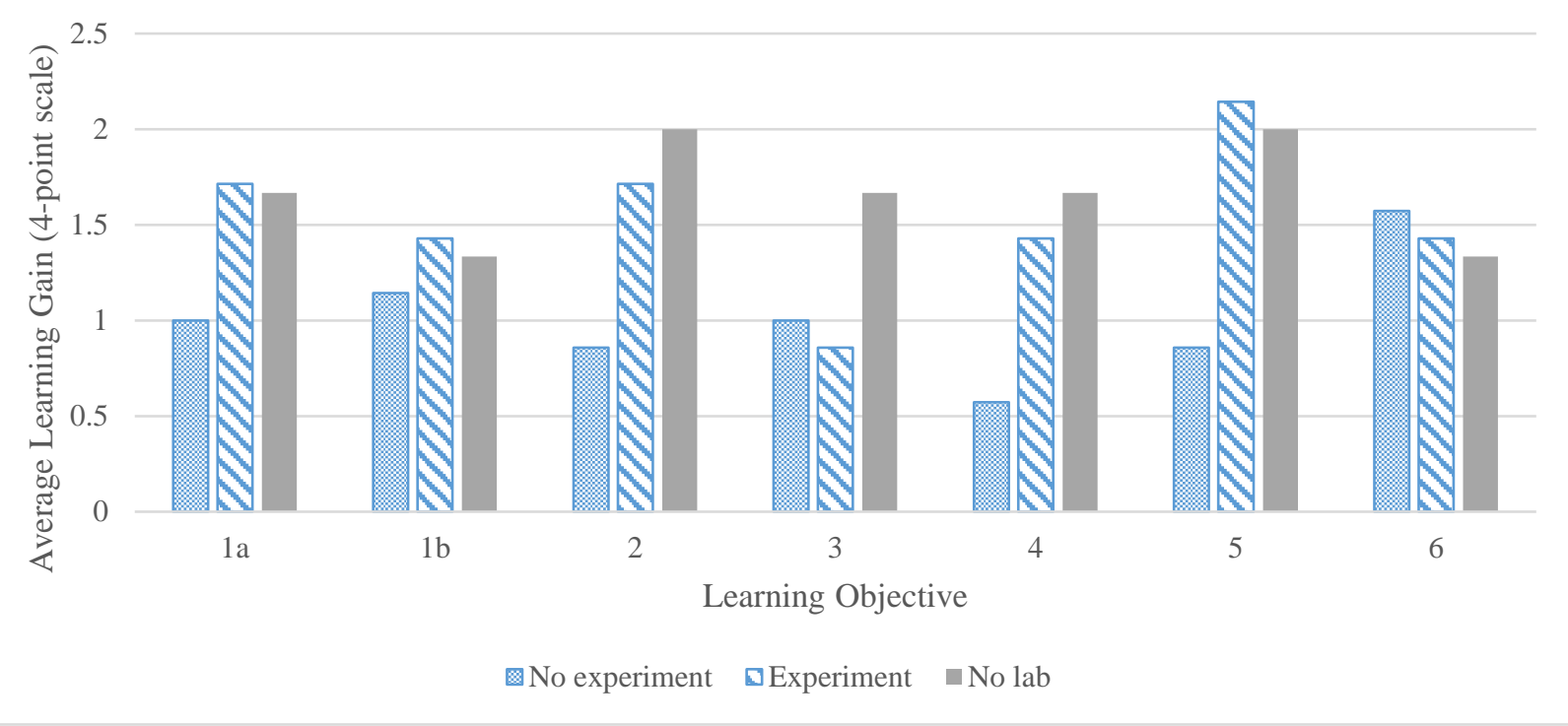

Figure 6. Average learning gain for each learning objective per laboratory section

Given the small sample size of the "No lab" group (only three students), it is inappropriate to draw strong conclusions from these results. However, because the learning gains reported by these students are similar to the "Experiment" group, these data indicate that perhaps the learning gains made by students in an online learning environment may approach those of students in a hands-on laboratory experience. The "No lab" students reported a greater ability than the other students to perform the learning objectives for every objective except (4) Describe the parameters that affect the damping ratio of a structure, which is expected because there was no content in the materials supplied to these students that addressed this aspect of dynamic response. This learning objective was addressed entirely during laboratory discussion in the other sections.

Student ratings of the learning experience, technology, instructor and facilities are provided in Figure 7. These ratings are most interesting because the "No lab" section that received the least interpersonal, physical and direct instruction rated all categories the highest. The "Experiment" students rated the learning experience slightly lower than the "No experiment" students, while the technology was rated similarly, perhaps indicating that the challenges overcome during the actual conducting of the experiment by the "Experiment" students were not perceived as valuable, while the "No experiment" students had the benefit of reviewing data that had already been collected and were not exposed to the challenges of that data collection. 
The students participating in the "No Experiment" section reported nearly unanimously regarding the "Least Effective" portion of the laboratory. In summarization of the comments received, the students felt that participating in the setup, conduct and data collection would have significantly increased the overall effect of the laboratory focus on real-world bridge evaluation. As perceived by several students in the "No Experiment" and "No Lab" sections, engineering students feel hindered by the lack of connection to field or practical experience. In the "Experiment" section, students responding to the "Least Effective" survey question were primarily concerned with time constraints and the lack of pertinent dynamics or vibrations knowledge prior to the laboratory session.

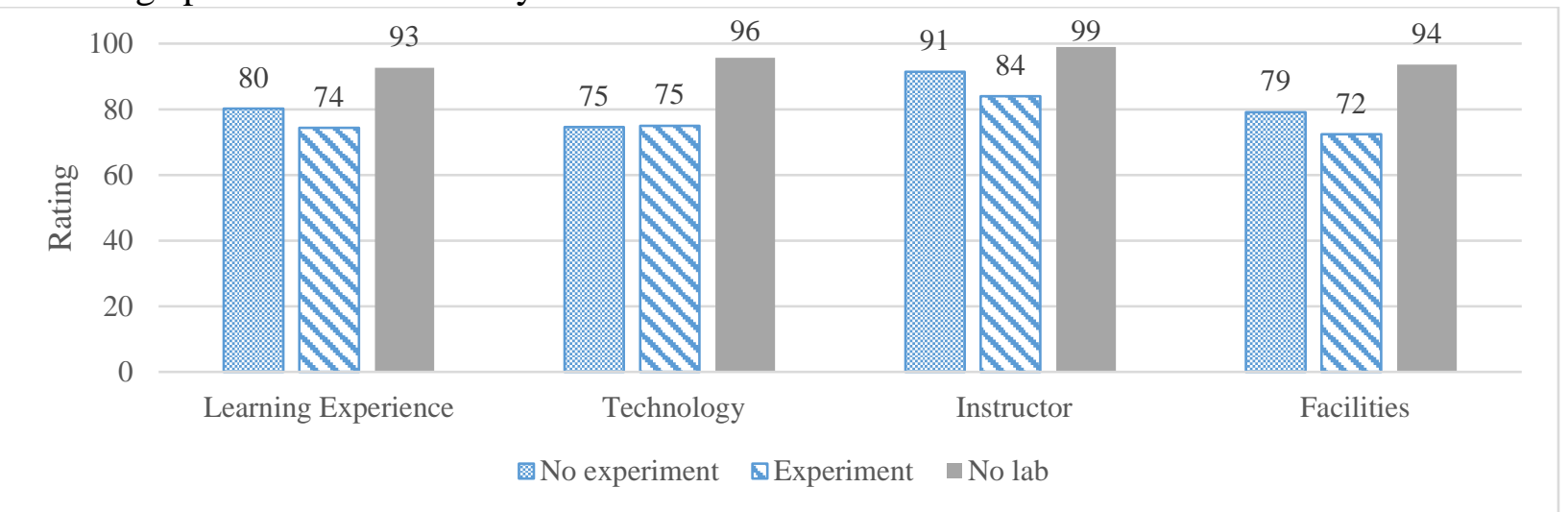

Figure 7. Average rating of learning experience, technology, instructor and facilities by the three laboratory sections (No experiment, Experiment, and No lab)

Students were nearly unanimous in their survey responses that the use of devices like the iPod for taking relevant measurements in the laboratory was valuable. This response was independent of the laboratory section and whether students had actually used the device. Specifically, when asked if the use of the iPod in this particular lab made it worse (1), the same (2), or better (3), all students indicated the same or better, with more responses indicating better (Figure 8 ). The use of devices like the iPod in laboratories in general received similar responses. Students also indicated that it would be even better if they were able to use their own device to conduct laboratory experiments.

Students' comments further supported the conclusion that devices used in the classroom in this way are beneficial. When describing the "Most Effective" aspects of the learning environment, one student in the "No Experiment" section described the use of mobile devices as, "Using phones as equipment is effective in making the work feel more within my own reach.” Just knowing that it was a mobile device that collected the data made the material more accessible to this student. 


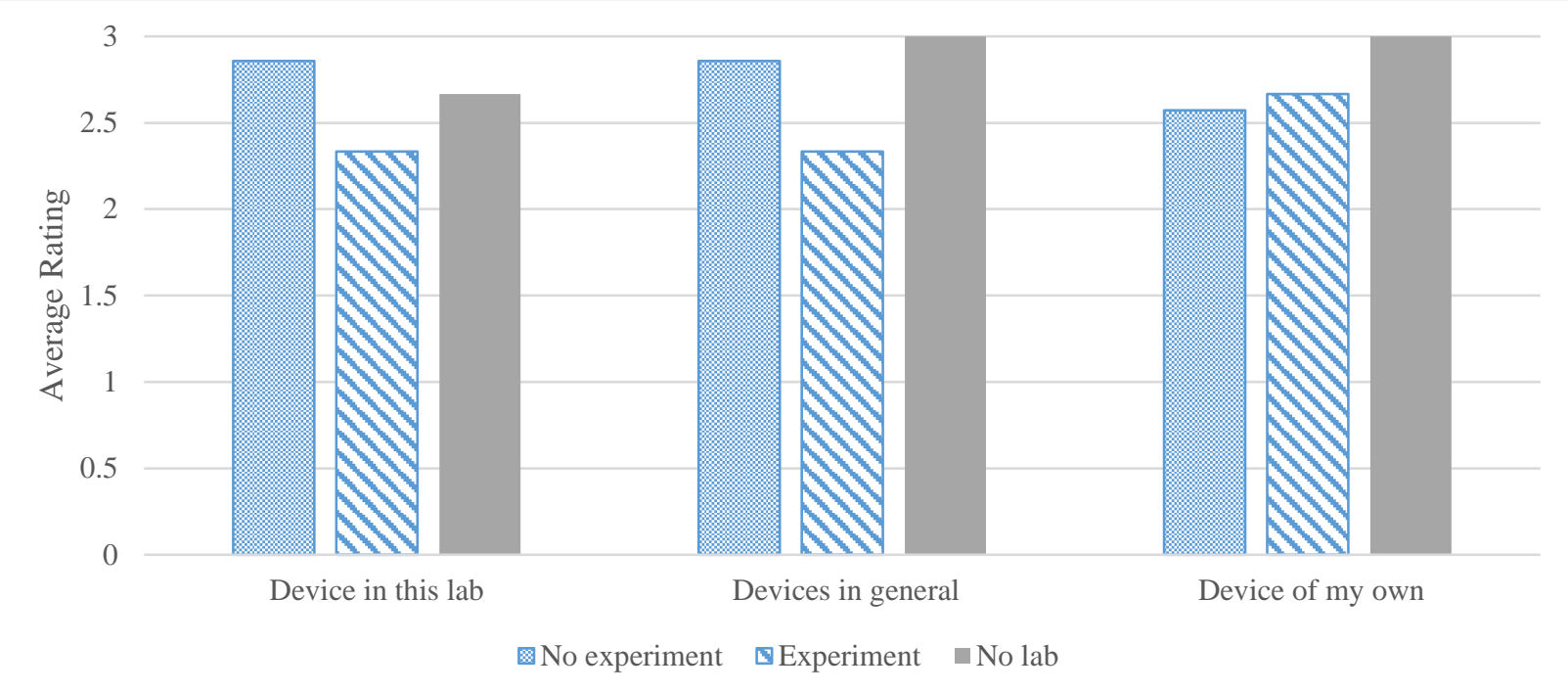

Figure 8. Student responses regarding the value of devices compared to a traditional lab - device made it or would make it worse (1), the same (2), or better (3)

Students were asked about their comfort repeating a similar experiment and analysis in a laboratory and field setting (Figure 9). Students in the "Experiment" group indicated they would be more comfortable than the "No experiment" group in a lab setting, but also indicated they would be less comfortable in a field setting, perhaps because they were more aware of the complicating factors. Many of the "Experiment" students indicated in their laboratory reports more nuanced challenges that one might face in a field setting, perhaps because of their more complete experience setting up and managing the experiment and data collection. The confidence expressed by the "No lab" students may be attributed to "ignorance is bliss." Without a detailed description of challenges or a hands-on experience, they may think the process is easier to replicate than those students who actually conducted the experiment or heard the instructor describe the challenges one might face in the field.

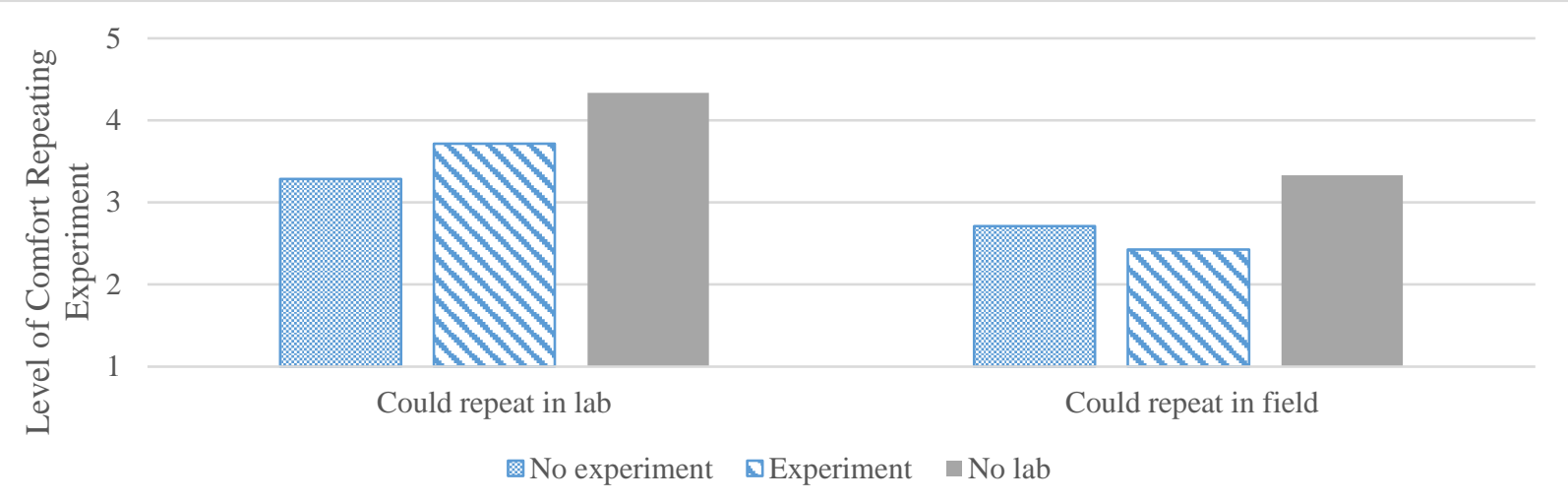

Figure 9. Student self-reported comfort repeating the laboratory procedure in lab and field scenarios ( $1=$ Not comfortable, $2=$ Somewhat comfortable, $3=$ Somewhat comfortable, $4=$ Comfortable, $5=$ Very comfortable)

Finally, a rigorous analysis of the data was conducted. Because of the low number of participants, non-parametric statistics were employed to compare the three groups. Students' 
rankings were summed across all learning objectives and compared between groups using Kruskal-Wallis tests. These tests revealed no significant differences between three groups before the experiment $(\mathrm{H}(2)=0.957, \mathrm{p}=0.617)$ or after the experiment $(\mathrm{H}(2)=4.867, \mathrm{p}=0.082)$, though the differences in post-experiment rankings did approach significance. The learning gains - the differences between the rankings before and after the experiment - were also compared and revealed no significant difference $(\mathrm{H}(2)=3.036, \mathrm{p}=0.215)$. The proficiencies on the lab memos, as graded by the instructor, also were not significantly different $(H(2)=0.827, p=0.654)$.

Further investigations did reveal one significant result. Specifically, there were significant differences in the learning gains for Objective $4(\mathrm{H}(2)=6.181, \mathrm{p}<0.025)$. It was presumed that a deeper analysis of these data would suggest that the "Experiment" group had performed better than the "No Experiment" group. After using a Bonferroni correction and thus reducing alpha to 0.025 for both tests, a one-tailed Mann-Whitney test did show that the "Experiment" group had significantly higher learning gains $(\mathrm{Zu}=2.289, \mathrm{p}<0.025)$ when asked to rate their ability to "Describe the parameters that affect the damping ratio of a structures." This may be due to the "Experiment" group's experience with the physical system, which allowed them to observe the damping of oscillations in real time rather than solely in plotted data.

\section{Conclusion}

Overall, the student response to this laboratory was positive and the demonstration of learning gains was both perceptible by the students through self-reporting and demonstrated by the students in their laboratory report submission. As an introductory module, the laboratory experiment has the benefit of simulating a significant real-world problem (structural deterioration and damage detection) as well as providing a platform for comparing theoretical and experimental results.

The primary goal in conducting this laboratory research study was to address the research questions described in the Introduction section above. According to the laboratory report submissions and survey results, students overwhelmingly agreed that experiencing a certain degree of active learning is valuable in the connection of laboratory experimentation with realworld practical scenarios. Using devices in the classroom, while not identified as significant, appears to provide a beneficial connection that makes engineering principles more accessible, based on student survey comments. Based on this feedback, mobile devices in the classroom seem to foster enthusiasm for the topic.

In the process of completing this laboratory, several students reported a more enjoyable laboratory experience as a direct result of collaboration and teamwork. For example, a student in the "Experiment" section stated that "discussing the results as a group was more valuable to me than trying to muddle through the analysis on my own," when asked about the most effective aspect of the laboratory experiment. The learning gains reported by the "Experiment" section were more than $50 \%$ greater than the "No experiment" section, and student comments indicated that experiencing the laboratory demonstration either provided or would provide a much more valuable learning experience when compared to online delivery or computation-only section. The "No lab" section simulating the online delivery mode reported the highest learning gains, but did not have the challenge that the "No experiment" students did, namely analyzing data for an experiment they did not conduct but with the experimental apparatus available nearby. Although 
the online ("No lab”) group reported a relatively high degree of satisfaction without participating in the demonstration, the comments received from these students reveal a certain sense of hindrance with respect to understanding the overall intention and connection of this experiment to structural health monitoring.

As a result of this research into the effect of alternative learning techniques and device utilization in the classroom, the data observed and recorded reveal a positive connection between participation in an active learning environment, laboratory performance, and enthusiasm for the topic. Engineering students in the study prefer participating in a hands-on experiment that encourages the connection between theoretical and practical experiences, with the additional benefit of utilizing personal mobile devices for data collection to facilitate damage detection. Following the completion of this laboratory in three alternative learning environments, further research will be conducted regarding using mobile devices to teach structural dynamics and structural health monitoring. Subsequent research will also focus on the practical application of mobile devices in field scenarios and the ability to utilize mobile device data collection for damage detection in structural health monitoring.

The use of devices was widely regarded as a positive aspect of this laboratory. As a result of this study, the instructor will continue developing laboratories that employ mobile devices like smartphones and iPods to gather data. Students expressed interest in exploring their curiosities using the devices as a result of learning about the capability of their devices. While it seems logical that greater learning can result from asking questions and having good tools with which to measure, students may not be aware of the power of the devices they have in their pockets.

\section{Acknowledgements}

The authors would like to recognize the support of the National Institute for Transportation and Communities (Task Order \# NITCN-OIT-06).

\section{References}

1. Chopra, Anil. Dynamics of Structures, $2^{\text {nd }}$ Ed. New Jersey: Pearson Prentice Hall, 2007.

2. Feisel, Lyle D., and Albert J. Rosa. 2005. "The Role of the Laboratory in Undergraduate Engineering Education." Journal of Engineeing Education 121-130.

3. Herrington, J., A. Herrington, J. Mantei, I. Olney, and B. Ferry. 2009. "Using mobile technologies to develop new ways of teaching and learning." Murdoch Research Repository (Murdoch Research Repository) 1-14.

4. Hopfner, Hagen, Guido Morgenthal, Maximilian Schirmer, Marcel Naujoks, and Christoph Halang. 2013. "On Measuring Mechanical Oscillations using Smartphone Sensors - Possibilities and Limitation ." ACM SIGMOBILE Mobile Computing and Communications Review 1-11.

5. Prince, Michael J., and Richard M. Felder. 2006. "Inductive Teaching and Learning Methods: Definitions, Comparisons, adn Research Bases." Journal of Engineeering Education 123-138.

6. Prince, Michael. "Does Active Learning Really Work? A Review of the Research.” In Journal of Engineering Education, July 2004.

7. Wenzel, Helmut. 2009. Health Monitoring of Bridges. Hoboken, NJ: Wiley. 
8. Work, Daniel B., and Alexandre M. Bayen. 2008. "Impacts of the Mobile Internet on Transportation Cyberphysical Systems: Traffic Monitoring using Smartphones." National Workshop for Research on High-Confidence Transportation Cyber-Physical Systems: Automotive, Aviation and Rail . 


\section{Appendix}

Laboratory Handout

CE449/549 Bridge Design

Bridge Dynamics Laboratory: Natural Frequency, Damping, and Damage Detection

Learning Objectives - After completing this laboratory you should be able to

1. Identify the natucal frequency and period of a freely vibrating single degree-of-freedom (SDF) system using

a. Measurement of free vibration with an initial displacement

b. Calculation with system stiffness and mass parameters

2. Identify the damping ratio of a freely vibrating SDF system by supplying an initial displacement and analyzing the log decrement of the measured response

3. Describe the effect of mass and stiffness on the natural frequency and natural period of a SDF system

4. Describe the parameters that affect the damping ratio of a structure

5. Analyze dynamic response data to determine the natural period and damping ratio of a structure

6. Evaluate the ability of multiple dynamic evaluations to identify damage in a structure

\section{Reading}

- Chopra, Chapter 1 - Equations of Motion, Problem Statements, and Solution Methods

- Chopra, Chapter 2-Free Vibration

\begin{tabular}{|c|l|c|}
\hline Symbol & Description & Units \\
\hline$\zeta$ & Damping ratio & - \\
\hline$f_{n}$ & Cyclic natural frequency (undamped) & $\mathrm{Hz}$ \\
\hline$u_{0}$ & Initial Displacement & $\mathrm{in}$ \\
\hline$u_{i}$ & Displacement at $i$ t'b peak; displacement at time $i$ & $\mathrm{in}$ \\
\hline$\dot{u}_{i}$ & Velocity at time $i$ & $\mathrm{in} / \mathrm{sec}$ \\
\hline$\ddot{u}_{i}$ & Acceleration at $i$ 't b peak; acceleration at time $i$ & $\mathrm{in} / \mathrm{sec}^{2}$ \\
\hline$\omega_{D}$ & Circular natural frequency (damped) & $\mathrm{rad} / \mathrm{sec}$ \\
\hline$\omega_{n}$ & Circular natural frequency (damped) & $\mathrm{rad} / \mathrm{sec}$ \\
\hline$c$ & Damping coefficient & \\
\hline$k$ & Stiffness or spring constant & $\mathrm{lb} / \mathrm{in}$ \\
\hline$m$ & Mass & $\left(\mathrm{lb}-\mathrm{s}^{2}\right) / \mathrm{ft}$ \\
\hline$p(t)$ & External force & $\mathrm{lb}$ \\
\hline$t$ & Time & $\mathrm{sec}$ \\
\hline$T_{D}$ & Natural period (damped) & $\mathrm{sec}$ \\
\hline$T n$ & Natural period (undamped) & $\mathrm{sec}$ \\
\hline$\rho$ & Beam-to-stiffiness ratio & - \\
\hline
\end{tabular}




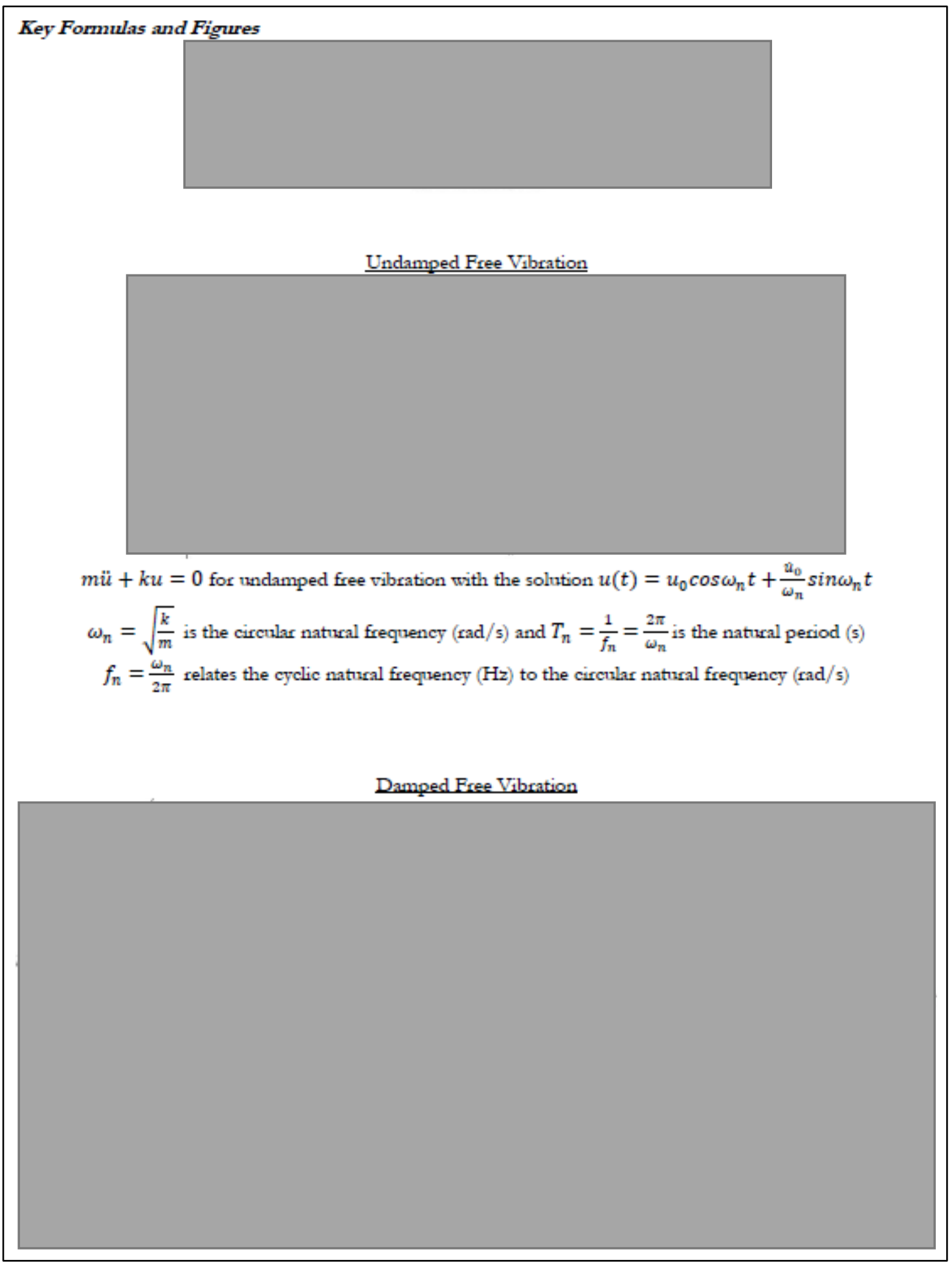




$$
\begin{gathered}
m \ddot{u}+c \dot{u}+k u=0 \text { for damped free vibration with underdamped solution } \\
u(t)=e^{-\zeta \omega_{n} t}\left[u_{0} \cos \omega_{D} t\right]+\frac{\tilde{u}_{0}+\zeta \omega_{n} u_{0}}{\omega_{D}} \sin \omega_{D} t
\end{gathered}
$$

Where the natural frequency of damped vibration $\omega_{D}=\omega_{n} \sqrt{1-\zeta^{2}}$ and damping ratio $\zeta=\frac{c}{2 m \omega_{n}}$

The damping ratio can be measured experimentally by examining the logarithmic decrement:

$$
\begin{gathered}
\delta=\ln \frac{u_{i}}{u_{i+1}}=\frac{2 \pi \zeta}{\sqrt{1-\zeta^{2}}} \text { where } u_{i} \text { and } u_{i+1} \text { are successive peak values of displacement } \\
\zeta=\frac{1}{2 \pi j} \ln \frac{u_{i}}{u_{i+j}} \text { evaluated over } j \text { cycles }
\end{gathered}
$$

\section{Part 1-Experimental Evaluation}

1. Set up a cantilever timber beam of known stiffness with C-clamps on the structural lab frame and attach an iPod or smart phone loaded with the iSeismometer app at the tip of the span. Be careful to protect your screen but maintain access to the play/pause button on the app.

2. Determine accurate measurements for unit weight ( $(\mathrm{b} / \mathrm{in})$, effective cantilever length (in), dimensions of the beam (in), elastic modulus, and moment of inertia for your beam.

3. Start the iSeismometer app recording acceleration data and immediately pluck the beam to excite the first mode of vibration.

4. Once a sufficient number of oscillations have been recorded, stop the recording and email the data to yourself for distribution to your colleagues.

5. Use the data to caleulate the natural frequency, period and damping ratio of the model.

\section{Part 2-Analytical Evaluation}

1. Prepare clear figures describing the geometry of each of the experiments you have conducted including the location of phones and additional weights. Measure the weight of the device you used to measure response. Measure cross section dimensions and calculate necessary properties. Estimate material properties for the cantilever element.

2. Use the procedures outlined in Chopra Chapters 1 and 2 and the spreadsheet available on Blackboard to calculate the theoretical natural frequency, period and damping ratio of the different structures you tested.

\section{Part 3-Damage Detection}

1. Using the same span and beam you used in parts 1 and 2, inflict approximately $25 \%$ section loss in the bottom chord of the beam and repeat the measurement and calculation of natural frequency, period and damping ratio.

2. Using the provided circular saw, adjust the cutting depth to allow for a $25 \%$ section loss with a measuring tape. Following your cut, record the actual depth with a caliper depth gatuge.

3. Repeat this process for $50 \%$ section loss, by adjusting the circular saw blade and repeating the cut to provide a greater depth in the previous cut.

4. Analyze the resulting data and indicate your ability to measure section loss with these results.

5. Discuss potential benefits and challenges to using this process in a field scenario.

\section{Submission - Hard copy due Wednesday by 5 pm next week}

Prepare a technical memorandum that summarizes your procedure, and presents your results and conclusions. Were you able to successfully conduct the experiment? Answer 4 and 5 from Part 3 thoroughly. Address any sources of error or uncertainty. Attach well-formatted results to your memorandum to support your commentary. 
Survey

Thank you for completing this survey regarding the Bridge Dynamics Laboratory: Natural Frequency, Damping, and Damage Detection, conducted during week 2 of Winter term in CE449/CE549 Bridge Design.

In which laboratory section did you participate?

CE549, Monday afternoon

c CE449, Thursday afternoon

None, I was travelling to TRB.

BEFORE participating in the lab last week, describe your ability to do the following things?

\begin{tabular}{|c|c|c|c|c|c|}
\hline & Poor & Fair & Good & Excellent & Not sure \\
\hline $\begin{array}{l}\text { Identify the natural } \\
\text { frequency and period of a } \\
\text { freely vibrating single } \\
\text { degree-of-freedom (SDF) } \\
\text { system using measurement } \\
\text { of free vibration with an } \\
\text { initial displacement }\end{array}$ & 0 & 0 & - & $\circ$ & 0 \\
\hline $\begin{array}{l}\text { Identify the natural } \\
\text { frequency and period of a } \\
\text { freely vibrating single } \\
\text { degree-of-freedom (SDF) } \\
\text { system using calculation } \\
\text { with system stiffness and } \\
\text { mass parameters }\end{array}$ & 0 & $\circ$ & ○ & - & 0 \\
\hline $\begin{array}{l}\text { Identify the damping ratio of } \\
\text { a freely vibrating SDF } \\
\text { system by supplying an } \\
\text { initial displacement and } \\
\text { analyzing the log } \\
\text { decrement of the measured } \\
\text { response }\end{array}$ & $\circ$ & $\circ$ & $\circ$ & 0 & 0 \\
\hline $\begin{array}{l}\text { Describe the effect of mass } \\
\text { and stiffness on the natural } \\
\text { frequency and natural } \\
\text { period of a SDF system }\end{array}$ & $\circ$ & $\circ$ & ○ & $\circ$ & 0 \\
\hline $\begin{array}{l}\text { Describe the parameters } \\
\text { that affect the damping ratio } \\
\text { of a structure }\end{array}$ & 0 & $\circ$ & 0 & - & 0 \\
\hline $\begin{array}{l}\text { Analyze dynamic response } \\
\text { data to determine the } \\
\text { natural period and damping } \\
\text { ratio of a structure }\end{array}$ & 。 & 0 & $\circ$ & 0 & - \\
\hline $\begin{array}{l}\text { Evaluate the ability of } \\
\text { multiple dynamic } \\
\text { evaluations to identify } \\
\text { damage in a structure }\end{array}$ & 0 & $\circ$ & $\circ$ & $\circ$ & $\circ$ \\
\hline
\end{tabular}


AFTER participating in the lab last week, describe your ability to do the following things?

\begin{tabular}{|c|c|c|c|c|c|}
\hline & Poor & Fair & Good & Excellent & Not sure \\
\hline $\begin{array}{l}\text { Identify the natural } \\
\text { frequency and period of a } \\
\text { freely vibrating single } \\
\text { degree-of-freedom (SDF) } \\
\text { system using measurement } \\
\text { of free vibration with an } \\
\text { initial displacement }\end{array}$ & 0 & 0 & 0 & 0 & 0 \\
\hline $\begin{array}{l}\text { Identify the natural } \\
\text { frequency and period of a } \\
\text { freely vibrating single } \\
\text { degree-of-freedom (SDF) } \\
\text { system using calculation } \\
\text { with system stiffness and } \\
\text { mass parameters }\end{array}$ & 0 & $\circ$ & 0 & $\odot$ & 。 \\
\hline $\begin{array}{l}\text { Identify the damping ratio of } \\
\text { a freely vibrating SDF } \\
\text { system by supplying an } \\
\text { initial displacement and } \\
\text { analyzing the log } \\
\text { decrement of the measured } \\
\text { response }\end{array}$ & 0 & 0 & 0 & 0 & $\circ$ \\
\hline $\begin{array}{l}\text { Describe the effect of mass } \\
\text { and stiffness on the natural } \\
\text { frequency and natural } \\
\text { period of a SDF system }\end{array}$ & 0 & $\circ$ & 0 & 0 & 0 \\
\hline $\begin{array}{l}\text { Describe the parameters } \\
\text { that affect the damping ratio } \\
\text { of a structure }\end{array}$ & 0 & 0 & $\circ$ & 0 & 6 \\
\hline $\begin{array}{l}\text { Analyze dynamic response } \\
\text { data to determine the } \\
\text { natural period and damping } \\
\text { ratio of a structure }\end{array}$ & 0 & - & 0 & 0 & 0 \\
\hline $\begin{array}{l}\text { Evaluate the ability of } \\
\text { multiple dynamic } \\
\text { evaluations to identify } \\
\text { damage in a structure }\end{array}$ & 0 & $\circ$ & ○ & 0 & 0 \\
\hline
\end{tabular}

With $0=$ low and $100=$ high, please rate the overall effectiveness of the

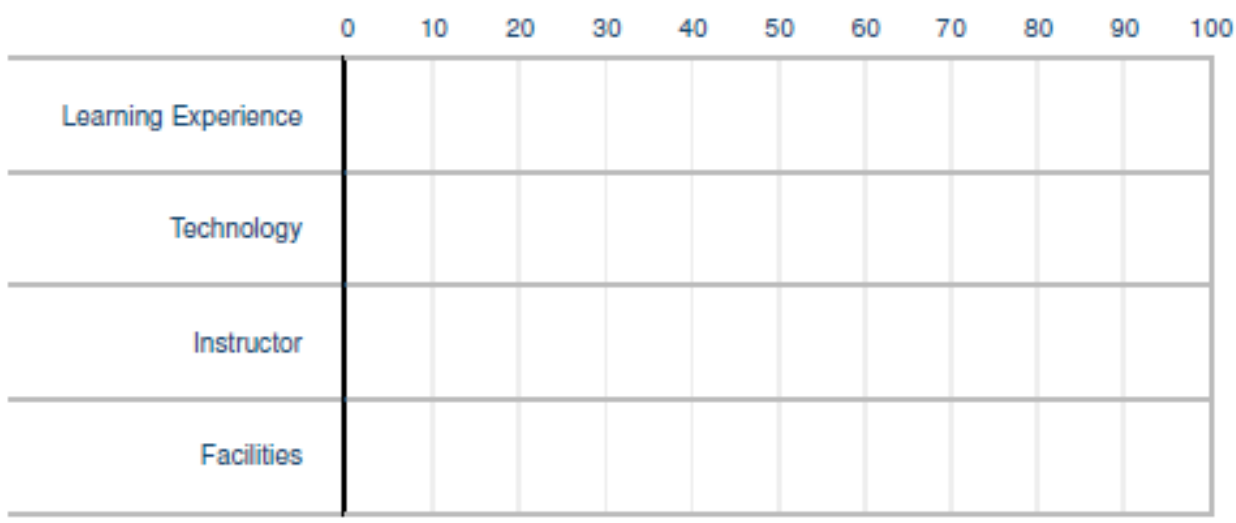




Regarding the use of an iPhone running the iSeismometer app to collect data, answer the following.
The use of the iPhone to
collect data made this lab
The use of devices like an
iPhone make labs
If I had my own device to
work with it would have
been

With little or no prior exposure to structural dynamics, how comfortable would you feel in repeating this procedure in

\begin{tabular}{|c|c|c|c|c|c|}
\hline & $\begin{array}{l}\text { Not at all } \\
\text { comfortable }\end{array}$ & $\begin{array}{l}\text { Somewhat } \\
\text { uncomfortable }\end{array}$ & $\begin{array}{l}\text { Somewhat } \\
\text { comfortable }\end{array}$ & Comfortable & $\begin{array}{c}\text { Very } \\
\text { Comfortable }\end{array}$ \\
\hline $\begin{array}{l}\text { a similar laboratory } \\
\text { experiment? }\end{array}$ & 0 & 0 & $\circ$ & $\circ$ & 6 \\
\hline a practicalfield situation? & 0 & $\circ$ & $\circ$ & $\circ$ & - \\
\hline Click to write Statement 3 & 0 & 0 & 0 & $\circ$ & 。 \\
\hline
\end{tabular}

Please list and explain the things you found MOST EFFECTIVE about the learning experience. 
Please list and explain the things you found LEAST EFFECTIVE about the learning experience.

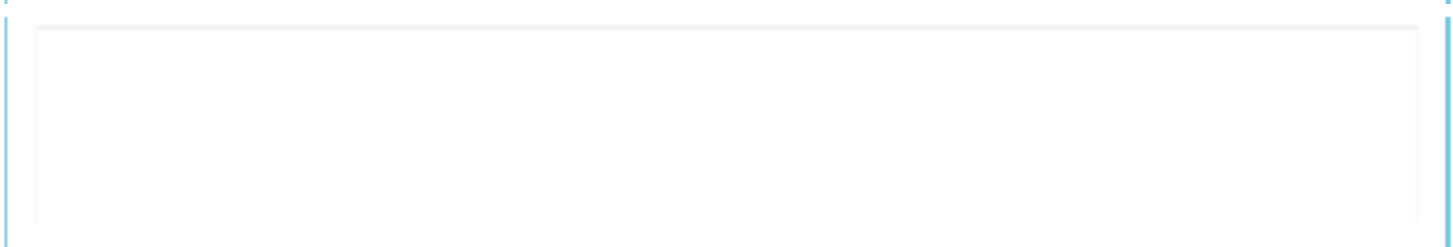

Please list and explain the things you found MOST EFFECTIVE about the instructor.

Please list and explain the things you found LEAST EFFECTIVE about the instructor.

Please list and explain any concrete suggestions for improving your learning in this particular laboratory. 
Student Written Responses to Survey Questions

Please list and explain the things you found MOST EFFECTIVE about the learning experience.

\section{Experiment}

\section{Text Response}

This lab put into perspective the effect damage has on structural members. We were able to see the decrease in strength of the 2"x4" member, and this enlightened me. I was able to envision processes of rusting, and how it can brutally take away from the strength of a steel member.

I liked being able to go into the lab and collect data, and then go back into the traffic lab to analyze the collected data. It gave me a better understanding of how the data is collected, and what it means, rather than just being given a set of numbers.

Actually going through the analysis process helped me understand what was going on better than the initial verbal description. Also discussing the results as a group was more valuable to me than trying to muddle through the analysis on my own.

The hands-on data collection.

Getting the data to work with via the seismometer.

Text Response $\quad$ experiment

I could picture the experiment and the concept was intriguing to me. I like participating in research.

Equations

We learned the equations and mechanics behind the excel spreadsheet and the graphs it generates. We saw the motion of the beam and the natural frequency it has, as well as the changes in the beams properties as it experienced damage.

Unique-- felt like I was participating in something that mattered--- felt like my work had more consequence than a typical lab, making work much more exciting and learning a more real experience. More interest in asking similar questions-- getting to participate in real research has inspired some inking of permission to explore my own curiosities as they arise, rather than simply accepting current practice as an absolute best practice. Phones-- Using phones as equipment is effective in making the work feel more within my own reach.

Explanation of the theoretical computations and how they relate to the test procedure and seeing similar results between theoretical and experimental results.

The procedure to determine the amount of damage was very helpful in learning the effects. Seeing and applying the formulas.

\section{No lab}

Text Response

Preparing the Excel sheet prior to lab was helpful in outlining the procedure for the lab and showed the steps to obtain the results.

Ability to compare results both theoretically and experimentally

The most effective part of this lab was the actual data being collected right in front of you.

This lab allowed for you to visually see the displacements and then view the data the seismometer collected, if I was present during the lab. 
Please list and explain the things you found LEAST EFFECTIVE about the learning experience Experiment

Text Response

I found not having the proper material the least effective portion of the lab. The structural member being tested already had damage. It is not that big of a deal, but it takes away from the lab, for labs are supposed to be controlled experiments.

I know that this was just a quick introduction into natural frequency, but I feel like I didn't completely understand the whole background behind damping and the properties that influence natural frequency.

Going through all the equations in the beginning, although good as an introduction, was a bit confusing and I didn't really understand what was happening until we actually did the analysis. I was really confused when we were trying to figure out what weight to put on the end of the beam.

Just a time restraint on the lab.

\section{No experiment}

Text Response

Excessive manipulation of data in Excel can be a bore, but this lab was not to bad. NA

I didn't collect the data... so the bit about that earlier isn't applicable. At times I was confused and lost... but it was possible to get reoriented and caught up. The explanation to somethings was confusing as I did not know what was what. Pictures and definitions would help.

Connection to general bridge design-- felt like an aside and didn't connect back to actual thesis if BRIDGE DESIGN. Three generated points of information leaves a lot of room for inconclusive reports, which is exciting, but not very academically rewarding in an immediate sense (especially when there's so much to learn, as it is). Derailment from scientific method-we didn't get to come up with our own hypothesis to test and compare with the results. We didn't get to ask our own questions-- Definitely felt like a sidecar experience, detracting from a genuine sense of ownership or consequence. Hand-held through the technical section-didn't get as much technical knowledge out of it because I felt that I was speculating rather than practicing, for better or worse.

Not performing the test procedure with iphone and beam.

The large amount of data for such a small experiment was the only hindrance. Not seeing the actual set-up since I was in the 449 lab.

\section{No lab}

Text Response

It was challenging to understand the relationship between the natural period, circular frequency, cyclic frequency, number of cycles, amplitude, and damping ratio.

Getting background information since I was gone

The least effective part of this for myself, was having to read about the procedure and piece together what took place in the lab to gather the data that was given to me. 
Please list and explain the things you found MOST EFFECTIVE about the instructor.

Text Response

The instructor conveys the information articulately and concise. This makes for an easier understanding of the material being taught.

His enthusiasm for the material, and the background he gave about how he was trying to do research on the subject.

Answers to questions and explanations of the process were good.

The in-depth explanation of the laboratory exercise.

The explanation of the whole lab generally, then going back and going through step by step \& answering questions along the way.

\section{No experiment}

Text Response

Clearly explaining the question, the method, and defining the objective.

NA

The technical knowledge, energy, and friendly mannor brought to the lab makes the otherwise opprobrious experience assistive.

His excitement-- the enthusiasm for discovering something new was infectious. Applying real data-- the two-part lab was actually really effective in feeling part of a real research project, saving us time in collection and focusing more on conclusions. It makes me wonder if it's better that the graduate students gathered and undergraduates discussed conclusions and evaluation. I think the other way around might be more appropriate, but we're all capable here at Oregon Tech.

Dr. Riley was very effective and detailed in explaining the processes and reasoning. Willingness to help.

\section{No lab}

\section{Text Response}

The written procedure handout was very helpful in understanding the concepts, procedures, and expected results of the lab.

His eagerness and excitement towards the material

The most effective part about the instructor is that he is very energetic and engaged with his teaching. Although it was difficult to visualize how the lab procedure was carried out, due to lab absence, he supplied us with a great amount of information that allowed myself to catch up to the class. 
Please list and explain the things you found LEAST EFFECTIVE about the instructor.

\section{CE549, Monday afternoon}

Text Response

His high ambitions sometimes puts a lot on our plates for lab, and we do not finish all the tasks required. But, I like that he has so much faith in us to accomplish everything he puts in front of us.

N/A

When we were running through the spreadsheet calculations, you were moving a little fast. I was able to keep up, but there were a few people that were falling behind.

It would be ideal to have the computer up near the screen and chalkboard to make points easier.

\section{CE449, Thursday afternoon}

\section{Text Response}

NA

Operates at a different level of understanding compared to some of the class...

Again-- didn't seem to tie very well to bridge design as much as rating or evaluation: just felt like an exploration of bridge mechanics, rather than a design situation, but maybe I'm getting ahead of myself

Some things said might be a little too fast for us to fully understand at the speed that you introduce the idea.

\section{None, I was travelling to TRB.}

\section{Text Response}

Some background information and practical field uses would be nice to learn about. This may have been discussed in class though.

Lots to do in the amount of time

I found that it was least effective for the instructor to have students pick their own points for viewing the dampening, as it was confusing for students to have different results and still be correct, but it is understandable as dampening varies with time. 
Please list and explain any concrete suggestions for improving your learning in this laboratory. Experiment

Text Response

I would suggest using the ram on the testing machine to put an initial displacement on the wood member. This then allows for a more controlled experiment. We then can put the same load each time we make a new cut to simulate damage.

Maybe making enough time during the lab to gather some more data or splitting into groups to test different scenarios. Like one group damages the beam close the support, one group does it in the middle, and another toward the cantilever end.

Making the lab a 2 or 3 part lab. Analyzing other structural members/structures.

Text Response $\quad$ experiment

I learn better when a lot is written on the board.

Pictures and definitions to specific vocabulary.

More emphasis on context-- there was a discussion of current bridge evaluation practices, but I feel it might be more effective to learn more about current bridge evaluation techniques first. Let us write our own hypothesis before we see the data (maybe read a prompt and come in with a hypothesis), to have some measuring stick. Required reading is tricky at Oregon Tech, though. You seem to have a lot listed, which is overwhelming and arguably dismissable. Then let us ask our own questions to explore, perhaps as a follow-up lab or term project.

Try slowing down on the excel spreadsheets. Sometimes it can be a little difficult to determine what to type in when you're a step ahead when we're still trying to discern what formula goes where and why that formula is being used.

I think it would have been more effective if the 449 lab period would have also got to see the experiment. I'm a visual learner so seeing it would have benefited me.

Text Response $\quad$ lab

This lab was presented very clearly, but I think it would have been more beneficial to attend the laboratory.

smaller class sizes are more effective

For travelers maybe a recording of the lab could have improved the understanding of the lab procedure. 

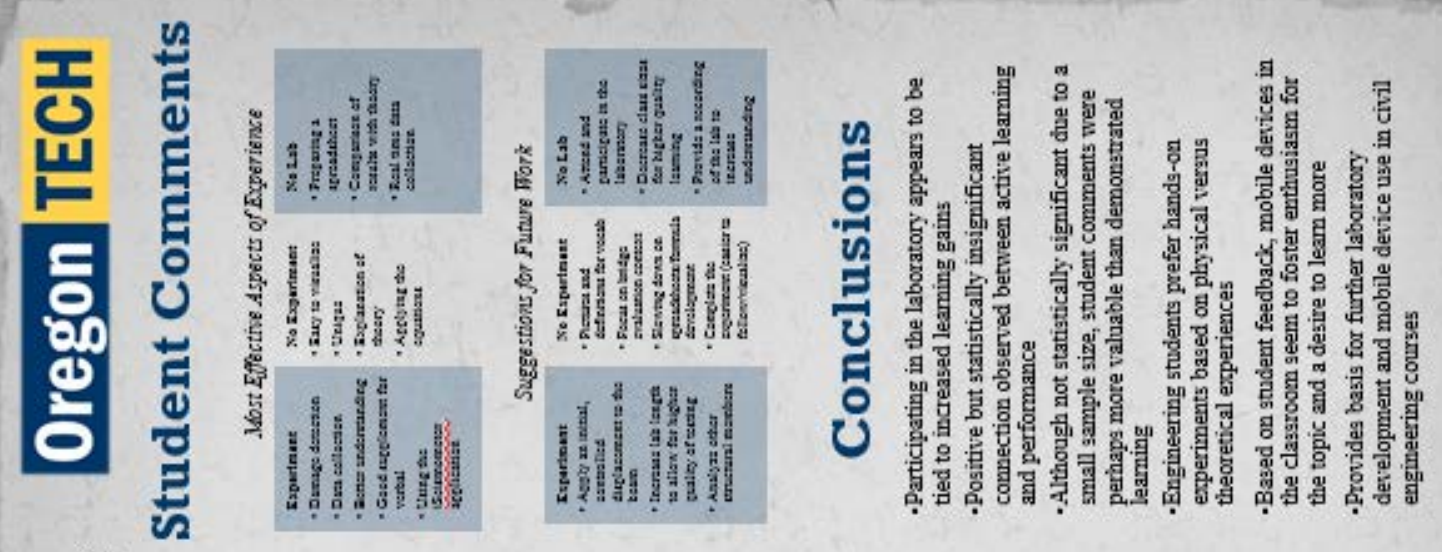

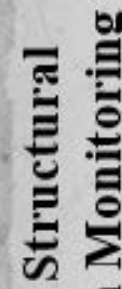

跸

年

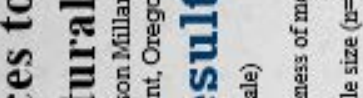

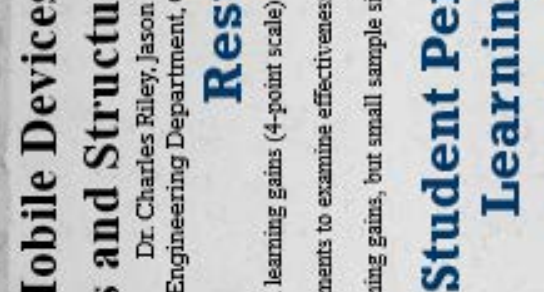

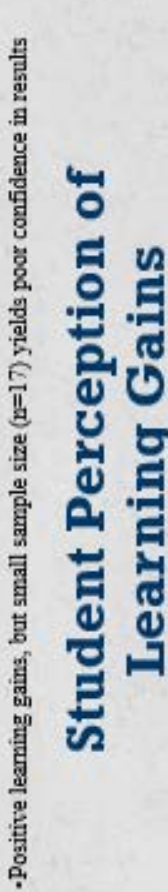

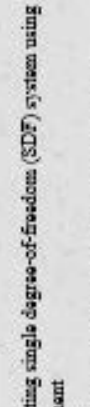

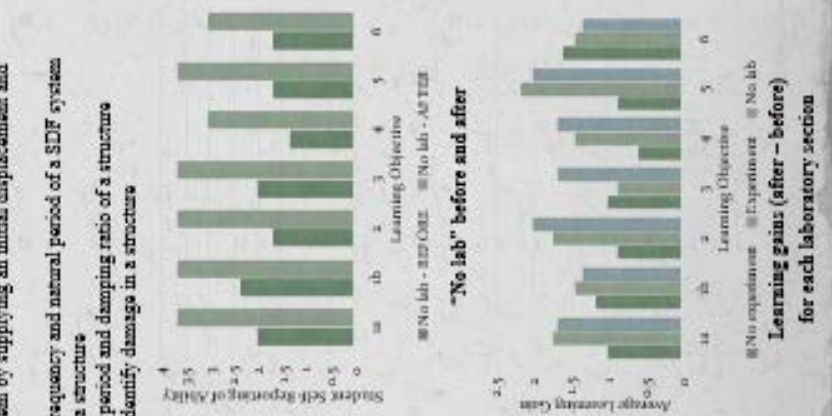

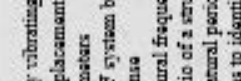

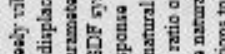

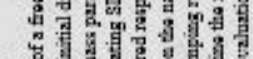

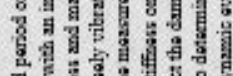

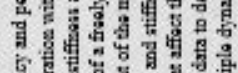

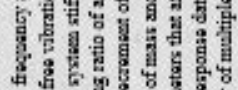

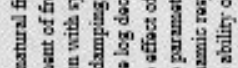

a

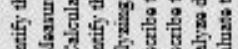

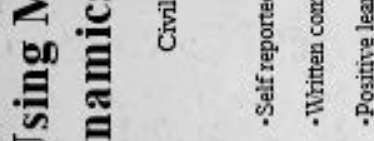

遗
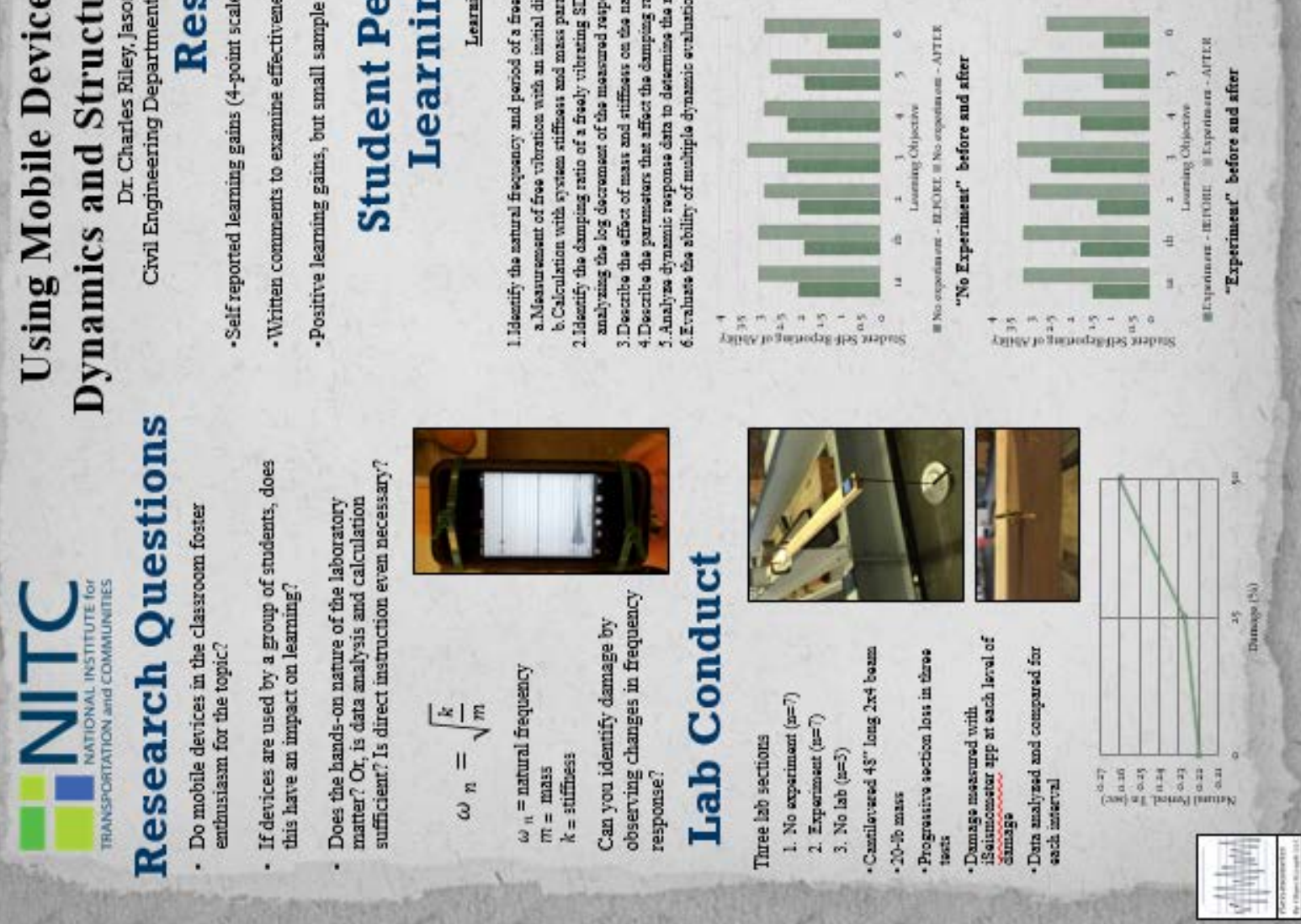


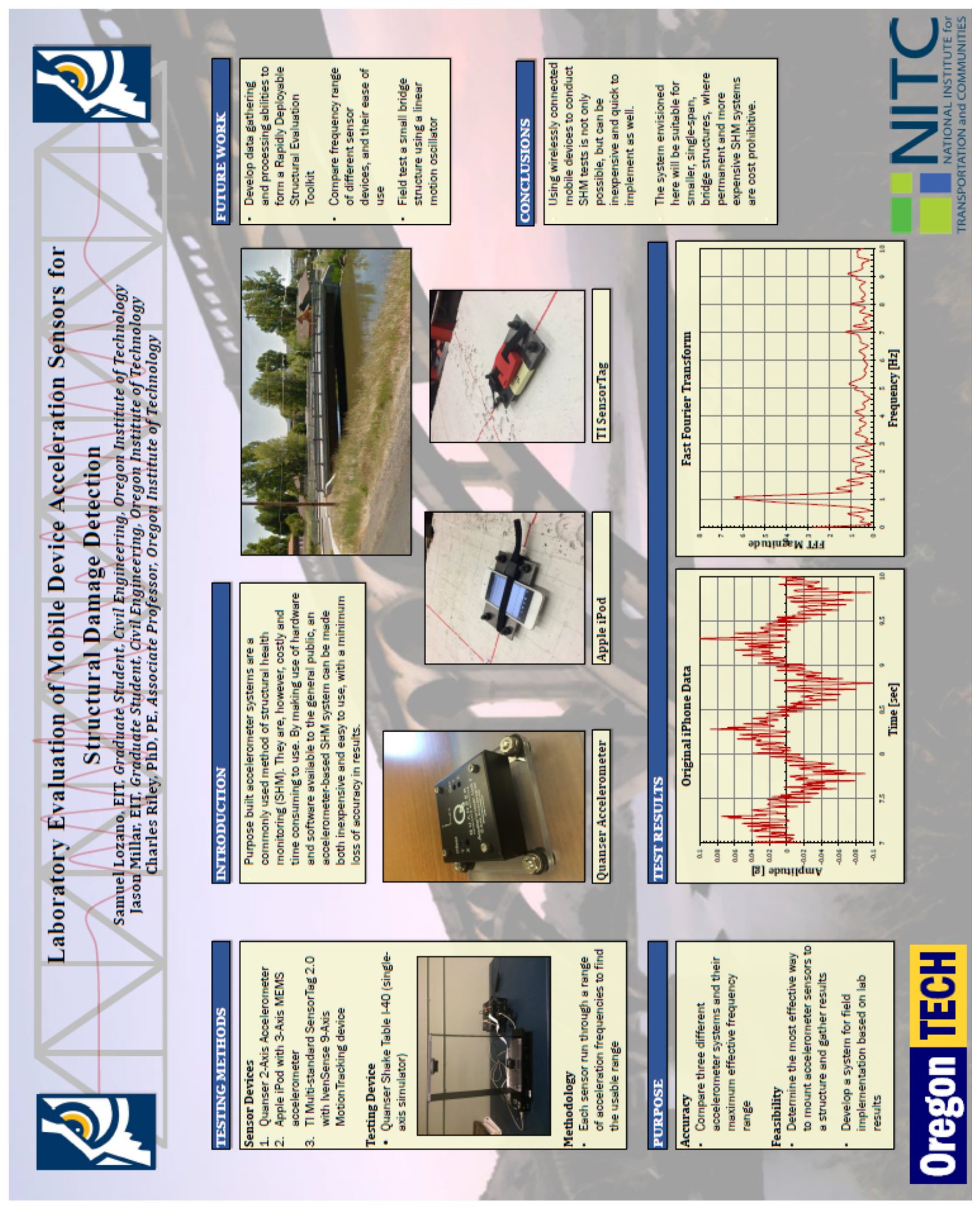


Transportation Research and Education Center

Portland State University

1900 S.W. Fourth Ave., Suite 175

Portland, OR 97201 